ORNL/TM--8999

DE86 013420

Engineering Physics and Mathematics Division

\title{
ACCELERATOR BREEDER NUCLEAR FUEL PRODUCTION: CONCEPT EVALUATION OF A MODIFIED DESIGN FOR ORNL'S PROPOSED TMF-ENFP
}

\author{
J. O. Johnson* \\ T. A. Gabriel \\ D. E. Bartine
}

Manuscript Completed: January 1985

Date of Issue: July 1986

* University of Tennessee

Department of Nuclear Engineering

Research sponsored by U.S. Department of Energy

Knoxville, TN 37916

Prepared by the Oak Ridge National Laboratory Oak Ridge, Tennessee 37831 operated by

Martin Marietta Energy Systems, Inc. for the

U.S. DEPARTMENT OF ENERGY under Contract No. DE-AC05-840R21400

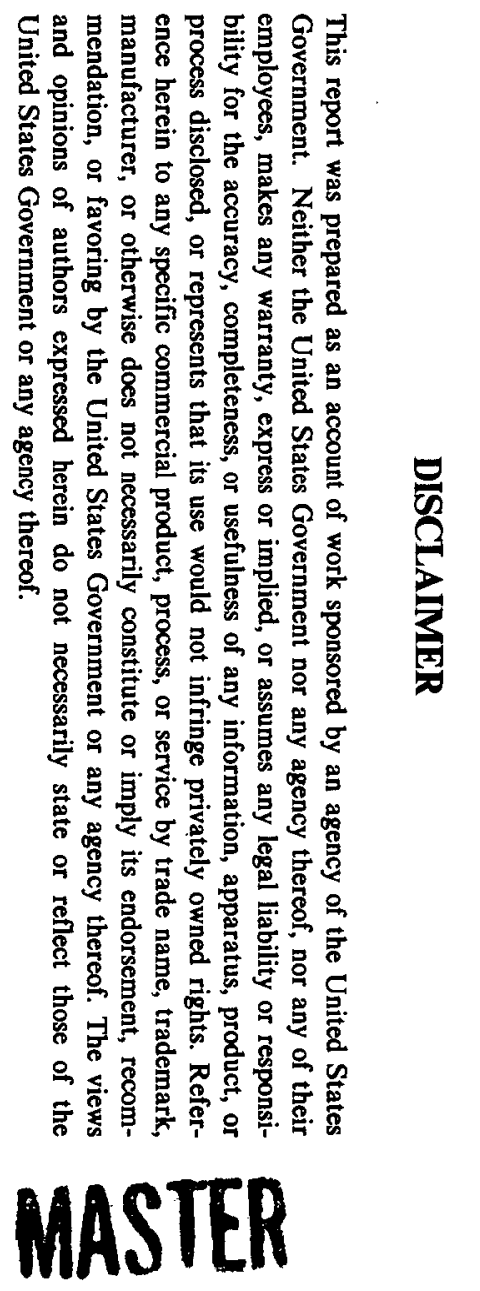




\section{DISCLAIMER}

This report was prepared as an account of work sponsored by an agency of the United States Government. Neither the United States Government nor any agency Thereof, nor any of their employees, makes any warranty, express or implied, or assumes any legal liability or responsibility for the accuracy, completeness, or usefulness of any information, apparatus, product, or process disclosed, or represents that its use would not infringe privately owned rights. Reference herein to any specific commercial product, process, or service by trade name, trademark, manufacturer, or otherwise does not necessarily constitute or imply its endorsement, recommendation, or favoring by the United States Government or any agency thereof. The views and opinions of authors expressed herein do not necessarily state or reflect those of the United States Government or any agency thereof. 


\section{DISCLAIMER}

Portions of this document may be illegible in electronic image products. Images are produced from the best available original document. 
Renewed interest in accelerator breeders as potential alternatives to fast breeder reactors surfaced briefly at Oak Ridge National Laboratory in the late 1970s; however, the interest subsided as plans for fuel reprocessing in the United States were delayed indefinitely. This report describes a follow-on study performed in 1983 to further refine and document an earlier ORNL proposal for possible future reference.

The authors appreciate the advice and assistance given by T. J. Burns during this study and by Lorraine S. Abbott during its documentation. Thanks also go to Angie Alford and Katie Ingersoll for their patience and skill in preparing the numerous drafts and the final manuscript. 


\section{TABLE OF CONTENTS}

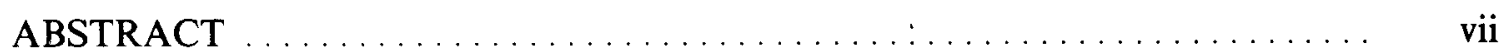

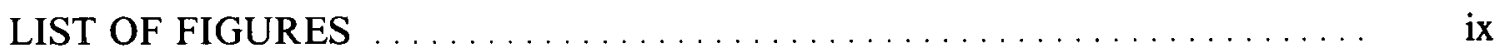

LIST OF TABLES $\ldots \ldots \ldots \ldots \ldots \ldots \ldots \ldots \ldots \ldots \ldots \ldots \ldots \ldots \ldots \ldots \ldots \ldots$

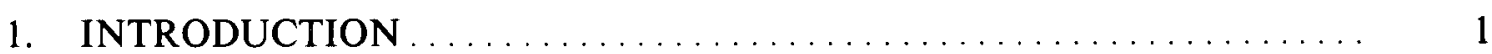

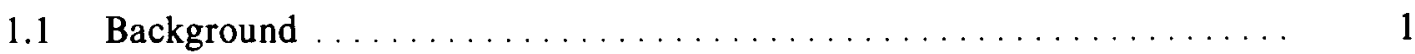

1.2 Objectives and Scope of This Investigation $\ldots \ldots \ldots \ldots \ldots \ldots \ldots \ldots$

2. TECHNICAL SUMMARY OF TMF-ENFP DESIGNS $\ldots \ldots \ldots \ldots \ldots \ldots \ldots$

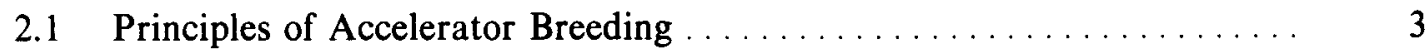

2.2 The Reference Accelerator Concept ...................... 3

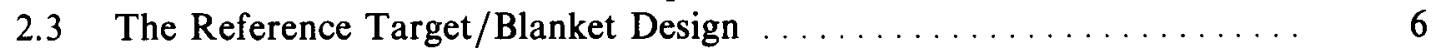

2.3.1 The Original TMF-ENFP Design ................. 7

2.3.2 The Modified TMF-ENFP Design $\ldots \ldots \ldots \ldots \ldots \ldots \ldots \ldots . \ldots . \ldots$

3. ANALYSIS METHODS AND CODES $\ldots \ldots \ldots \ldots \ldots \ldots \ldots \ldots \ldots \ldots$

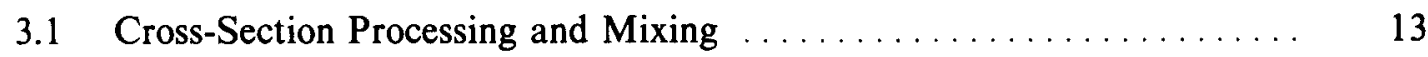

3.2 Two-Dimensional Transport Analysis ..................... 13

3.3 One-Dimensional Parameter Optimization Analysis .............. 18

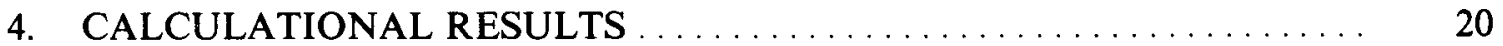

4.1 The High Energy Transport Results $\ldots \ldots \ldots \ldots \ldots \ldots \ldots \ldots \ldots \ldots . \ldots \ldots$

4.2 The Two-Dimensional Reference Design Results ................... 20

4.3 The One-Dimensional Parameter Optimization Results ........... 24

5. CONCLUSIONS AND RECOMMENDATIONS $\ldots \ldots \ldots \ldots \ldots \ldots \ldots . \ldots$

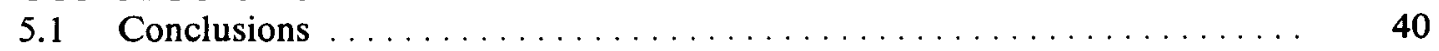

5.2 Recommendations .............................. 43

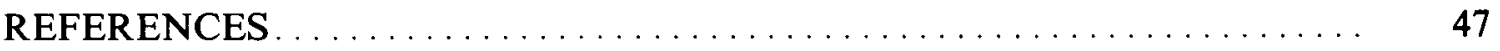




\begin{abstract}
Recent advances in accelerator beam technology have made it possible to improve the target/blanket design of the Ternary Metal Fueled Electronuclear Fuel Producer (TMFENFP), an accelerator-breeder design concept proposed by Burns et al. for subcritical breeding of the fissile isotope ${ }^{233} \mathrm{U}$. In the original TMF-ENFP the $300-\mathrm{mA}, 1100-\mathrm{MeV}$ proton beam was limited to a small diameter whose power density was so high that a solid metal target could not be used for producing the spallation neutrons needed to drive the breeding process. Instead the target was a central column of circulating liquid sodium, which was surrounded by an inner multiplying region of ternary fuel rods $\left({ }^{239} \mathrm{Pu},{ }^{232} \mathrm{Th}\right.$, and ${ }^{238} \mathrm{U}$ ) and an outer blanket region of ${ }^{232} \mathrm{Th}$ rods, with the entire system cooled by circulating sodium. In the modified design proposed here, the proton beam is sufficiently spread out to allow the ternary fuel to reside directly in the beam and to be preceded by a thin (nonstructural) V-Ti steel first wall. Thus the fuel itself acts as the target. The spread beam mandated a change in the design configuration (from a cylindrical shape to an Erlenmeyer flask shape), which, in turn, required that the fuel rods (and blanket rods) be replaced by fuel pebbles. The fuel residence time in both systems was assumed to be 90 full power days. A series of parameter optimization calculations for the modified TMFENFP led to a semioptimized system in which the initial ${ }^{239} \mathrm{Pu}$ inventory of the ternary fuel was $6 \%$ and the fuel pebble diameter was $0.5 \mathrm{~cm}$. With this system the ${ }^{233} \mathrm{Pu}$ production rate of $5.8 \mathrm{~kg} /$ day reported for the original TMF-ENFP was increased to $9.3 \mathrm{~kg} / \mathrm{day}$, and the thermal power production at beginning of cycle was increased from $3300 \mathrm{MW}(\mathrm{t})$ to $5240 \mathrm{MW}(\mathrm{t})$. Over the cycle length the $k_{\text {eff }}$ of the modified TMF-ENFP decreases slightly, which provides a safety feature, and the thermal power in the modified TMFENFP remains essentially constant over the cycle length, which facilitates a secondary side heat removal design. However, additional studies are needed to further optimize both the neutronic and the thermal-hydraulic performance parameters of the system. In particular, a flatter proton beam profile would alleviate radiation-damage and heat-transfer problems, which, in turn, would allow the first wall to be redesigned to serve as a structural component.
\end{abstract}




\section{LIST OF FIGURES}

Figure 1. Schematic of accelerator breeding process ............... 4

Figure 2. Neutron yield as a function of target material and proton energy .... 4

Figure 3. Energy required to liberate low-energy neutrons by high-energy proton bombardment of $\mathrm{Pb}$ target . . . . . . . . . . . . . . . . 5

Figure 4. Schematic diagram and outline characteristics of reference accelerator concept ........................... 6

Figure 5. Schematic diagram of the original TMF-ENFP . . . . . . . . . . . 7

Figure 6. Schematic diagram of the modified TMF-ENFP . . . . . . . . 11

Figure 7. Profile of proton beam incident on the target/blanket first wall ..... 12

Figure 8. Computational flow diagram for the neutronics and thermal-

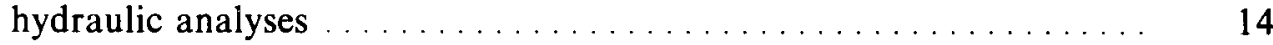

Figure 9. Two-dimensional DOT-4.3 model for the modified TMF-ENFP

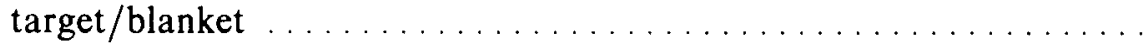

Figure 10. HETC cumulative distribution function of the incident proton beam distribution . . . . . . . . . . . . . . . . . . . . . . . 19

Figure 11. HETC neutron source spectrum .................. 21

Figure 12. Radial power density profiles of the first wall, sodium gap, and

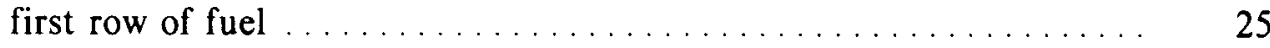

Figure 13. Radial power density profiles of the target/blanket approximately

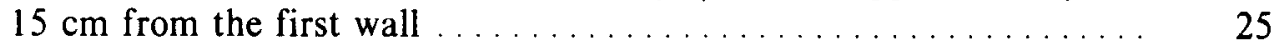

Figure 14. Axial power density profiles of the target/blanket at $R=0 \ldots \ldots$

Figure 15. One-dimensional transport model used in the parameter optimization study

Figure 16. Modified target/blanket thermal power as a function of cycle length and ${ }^{239} \mathrm{Pu}$ concentration

Figure 17. Modified target/blanket ${ }^{233} U$ production as a function of cycle length and ${ }^{239} \mathrm{Pu}$ concentration

Figure 18. Modified target/blanket ${ }^{232} \mathrm{U}$ production as a function of cycle length and ${ }^{239} \mathrm{Pu}$ concentration

Figure 19. Modified target/blanket ${ }^{228} \mathrm{Th}$ production as a function of cycle length and ${ }^{239} \mathrm{Pu}$ concentration

Figure 20. Modified target/blanket thermal power production for the $5 \%{ }^{239} \mathrm{Pu}$ ternary metal fuel as a function of reprocessing mode

Figure 21. Modified target/blanket ${ }^{233} \mathrm{U}$ production for the $5 \%{ }^{239} \mathrm{Pu}$ ternary metal fuel as a function of reprocessing mode 
Figure 22. Modified target/blanket ${ }^{232} \mathrm{U}$ and ${ }^{228} \mathrm{Th}$ production for the $5 \%{ }^{239} \mathrm{Pu}$ ternary metal fuel as a function of reprocessing mode

Figure 23. Forced convective heat-transfer coefficients as a function of sodium velocity and fuel pebble diameter.

Figure 24. Ternary metal fuel centerline temperature for the $3 \%{ }^{239} \mathrm{Pu}$ concentration as a function of sodium velocity and pebble diameter.

Figure 25. Ternary metal fuel centerline temperature for the $6 \%{ }^{239} \mathrm{Pu}$ concentration as a function of sodium velocity and pebble diameter

Figure 26. Hot-spot temperatures for a 0.5 -cm-thick first wall as a function of sodium velocity and pebble diameter

Figure 27. Hot-spot temperatures for a 0.4-cm-thick first wall as a function of sodium velocity and pebble diameter

Figure 28. Hot-spot temperatures for the first wall with reversed sodium flow as a function of sodium velocity and pebble diameter

Figure 29. Spatial map of the total flux from the modified TMF-ENFP target/blanket design

Figure 30. Spatial map of the ${ }^{239} \mathrm{Pu}(n, f)$ activity for the modified TMF-ENFP target/blanket design

Figure 31. Spatial map of the ${ }^{238} \mathrm{U}(n, \gamma)$ activity for the modified TMF-ENFP target/blanket design

Figure 32. Spatial map of the ${ }^{232} \mathrm{Th}(n, \gamma)$ activity for the modified TMF-ENFP target/blanket design 


\section{LIST OF TABLES}

Table 1. Original TMF-ENFP design parameters $\ldots \ldots \ldots \ldots \ldots \ldots \ldots \ldots$

Table 2. Summary of original TMF-ENFP neutronic and thermalhydraulic performance parameters $\ldots \ldots \ldots \ldots \ldots \ldots \ldots \ldots . \ldots$

Table 3. Modified TMF-ENFP design parameters $\ldots \ldots \ldots \ldots \ldots \ldots \ldots \ldots$

Table 4. Coupled $36 n-23 \gamma$ group structure and $3 n$ group structure . . . . . . 15

Table 5. Material compositions used in radiation transport analysis ........ 16

Table 6. Material composition of the ternary metal fuel as a function of

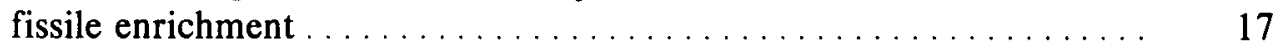

Table 7. HETC distribution of the proton beam energy deposited in the

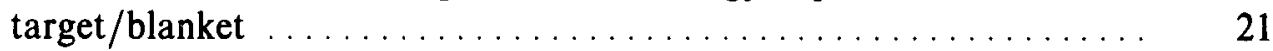

Table 8. Comparison of key performance parameters between the original and modified TMF-ENFP designs ............... 22

Table 9. Major reaction rates for the modified TMF-ENFP target/blanket design at beginning of cycle $\ldots \ldots \ldots \ldots \ldots \ldots$

Table 10. System multiplication and $k_{\text {eff }}$ results as a function of ${ }^{239} \mathrm{Pu}$ concentration in the ternary metal fuel

Table 11. Comparison of two-dimensional DOT-4.3 transport results and one-dimensional ORIGEN-S burnup results at beginning of cycle (BOC).

Table 12. Modified target/blanket performance as a function of ${ }^{239} \mathrm{Pu}$ concentration in the ternary metal fuel

Table 13. Design parameters of the semioptimized TMF-ENFP target/blanket design

Table 14. Summary of modified (semioptimized) TMF-ENFP neutronic and thermal-hydraulic performance parameters 


\section{INTRODUCTION}

Many studies ${ }^{1-4}$ project the need for an abundant source of fissile fuel if the commercial reactor power industry is to remain a long-term energy source for the world. The cost of this fissile fuel and the time frame in which it will be needed vary from one report to another; however, almost all reports agree on the following:

1. The uncommitted known resources and reserves of fissile material will not be sufficient to fuel the nuclear industry through the next century.

2. The introduction of spent fuel reprocessing and/or fast breeder reactors will not completely solve the problem.

3. The world has an abundant supply of fertile material $\left({ }^{232} \mathrm{Th}\right.$ and $\left.{ }^{238} \mathrm{U}\right)$ which if converted to fissile fuel $\left({ }^{233} \mathrm{U}\right.$ and $\left.{ }^{239} \mathrm{Pu}\right)$ would in all probability extend the lifetime of the nuclear power industry indefinitely.

Considerations of the third statement have led to proposals that an "out-of-pile" breeding technology be developed for converting fertile material to fissile material. Fundamentally, this involves using an independent external neutron source and breeding fuel in a system operating in a subcritical mode. Of the two technologies exhibiting the most potential for achieving this capability - the fusion-fission hybrid reactor and the accelerator breeder reactor - the accelerator breeder is considered the more viable because of technological problems associated with the fusion device. Like a fast breeder reactor, an accelerator breeder allows full energy utilization of uranium and thorium ores. In addition, it offers safety advantages over fast breeder reactors, provides a source of ${ }^{233} \mathrm{U}$ and/or ${ }^{239} \mathrm{Pu}$ without using ${ }^{235} \mathrm{U}$, and facilitates the development of fuel cycles which lessen the threat of fuel diversion and greatly reduce the volume of actinide waste.

\subsection{BACKGROUND}

The concept of producing fissionable material with an accelerator "breeder" is not new. Many experimental and theoretical programs ${ }^{5-12}$ dating back to the 1950 s and 1960 s have shown that the intense neutron sources required can be generated with accelerators, although the principal motivation governing the early work was aimed at obtaining sources for neutron cross-section measurements and other nuclear physics studies. As the commercial nuclear industry grew in the early 1970's, the attractiveness of using acceleratorproduced neutrons to breed fissile fuel became apparent, and more specific studies ${ }^{13-19}$ of accelerators for commercial breeding applications were initiated. At Oak Ridge National Laboratory, in particular, a 1977 study by Mynatt et al. ${ }^{16}$ investigated several different accelerator target/blanket design concepts, and a subsequent study by Burns et al. ${ }^{18}$ resulted in a specific design concept for producing ${ }^{233} \mathrm{U}$ in an accelerator breeder identified as the Ternary Metal Fueled Electronuclear Fuel Producer (TMF-ENFP). Calculations for the TMF-ENFP indicated that the target/blanket design would exhibit exceptional performance characteristics but, unfortunately, would be constrained by parameters associated with accelerator beam technology. 
Soon after the TMF-ENFP was proposed, it became possible to introduce innovative design changes in accelerator beams which would relax the constraining parameters affecting the TMF-ENFP. With this possibility, a new investigation was initiated to assess the impact of the beam improvements on the TMF-ENFP target/blanket design and breeding capabilities. This report describes the results of the new study.

\subsection{OBJECTIVES AND SCOPE OF THIS INVESTIGATION}

The objectives of the investigation described here were (1) to modify (improve) the TMF-ENFP target/blanket design as allowed by the recent advances in accelerator beam technology, at the same time retaining the design criteria and general nuclear characteristics associated with the original design, (2) to perform preliminary analyses of the new target/blanket neutronic and thermal-hydraulic characteristics to assess the practical utility of the modified accelerator beam design, and (3) to carry out an optimization study of the target/blanket performance with respect to its isotopic composition, cycle length, net fissile production, and reprocessing mode in order to facilitate future studies of target/blanket concepts.

The results of the investigation are described in Sections 2-5 below. After briefly discussing the basic processes in accelerator breeding, Section 2 describes the reference proton accelerator concept, the original TMF-ENFP target/blanket design, and the modified TMF-ENFP target/blanket design. Section 3 presents the computational methodology and models used in the neutronic and thermal-hydraulic analyses of the modified design, and Section 4 describes the results obtained. Finally, Section 5 gives the conclusions of the analyses, recommends improvements in the preliminary design which should be investigated in any future studies, and identifies research and development areas associated with the target/blanket design. 


\section{TECHNICAL SUMMARY OF TMF-ENFP DESIGNS}

\subsection{PRINCIPLES OF ACCELERATOR BREEDING}

The elemental processes in accelerator breeding are shown schematically in Fig. 1. Basically, a proton (or a deuteron) is accelerated to an energy of approximately $1 \mathrm{GeV}$ and directed onto a target nucleus. The resulting interaction produces many secondary particles in a cascade, including up to $50+$ neutrons that are used either directly or indirectly to convert fertile material into fissile material.

Many experiments ${ }^{8,10-12}$ have been performed to establish the products of the spallation process and also to determine the required incident proton beam energy necessary to achieve efficient neutron production. Figure 2 shows, for example, that the neutron production increases significantly as the incident proton energy increases and as the atomic weight and size of the target material increases. The amount of energy required to liberate a low-energy neutron also varies with the energy of the incident proton. Figure 3 shows that for a lead target the required liberating energy increases sharply with decreasing proton energy for incident protons having energies less than $1.0 \mathrm{GeV}$. This relationship has also been observed for other target materials. These data, together with data relating to beam loss, cost, reliability, etc., led to the selection of $1.0 \mathrm{GeV}$ as being the most efficient incident proton beam energy. ${ }^{14}$

In an accelerator breeder the spallation neutrons (Fig. 1) are directed onto a region consisting mainly of fertile material $\left({ }^{232} \mathrm{Th}\right.$ or $\left.{ }^{238} \mathrm{U}\right)$ but also possibly containing an initial inventory of ${ }^{239} \mathrm{Pu}$. Most of the neutrons are captured by the fertile material, producing the fissile isotopes ${ }^{233} \mathrm{U}$ and ${ }^{239} \mathrm{Pu}$. Fissions in the fissile material, coupled with some fast fission of the ${ }^{238} \mathrm{U}$, induce subcritical multiplication, ultimately increasing the production of neutrons to 20 to 200 per incident proton. These neutrons are subsequently absorbed in the fertile material, in further fission reactions, or in parasitic capture. The net fissile fuel production is determined by the number of breeding captures less the fission of the bred fissile material, with adjustments made for the initial fissile inventory, if any.

In addition to providing neutrons for breeding, the nuclear cascade process and the various neutron reactions also produce a large quantity of thermal energy that is deposited in the target/blanket region. This heat can be recovered and utilized to power the device, possibly to the point of obtaining energy self-sufficiency. Thus, in theory at least, an accelerator breeder could enhance the fissile fuel supply without placing any demands on outside energy sources.

\subsection{THE REFERENCE ACCELERATOR CONCEPT}

Prior to the development of the TMF-ENFP concept, studies by Bartholomew et al. ${ }^{9,14}$ had determined that the accelerator required for an efficient nuclear breeder should be able to deliver a continuous beam of $300 \mathrm{~mA}$ of $1100-\mathrm{MeV}$ protons to the target/blanket assembly. Linear accelerators are well suited to this application because of high current capability and low beam losses; however, the experimental accelerators in operation at present have not yet achieved both a high output energy and a high output current. The 


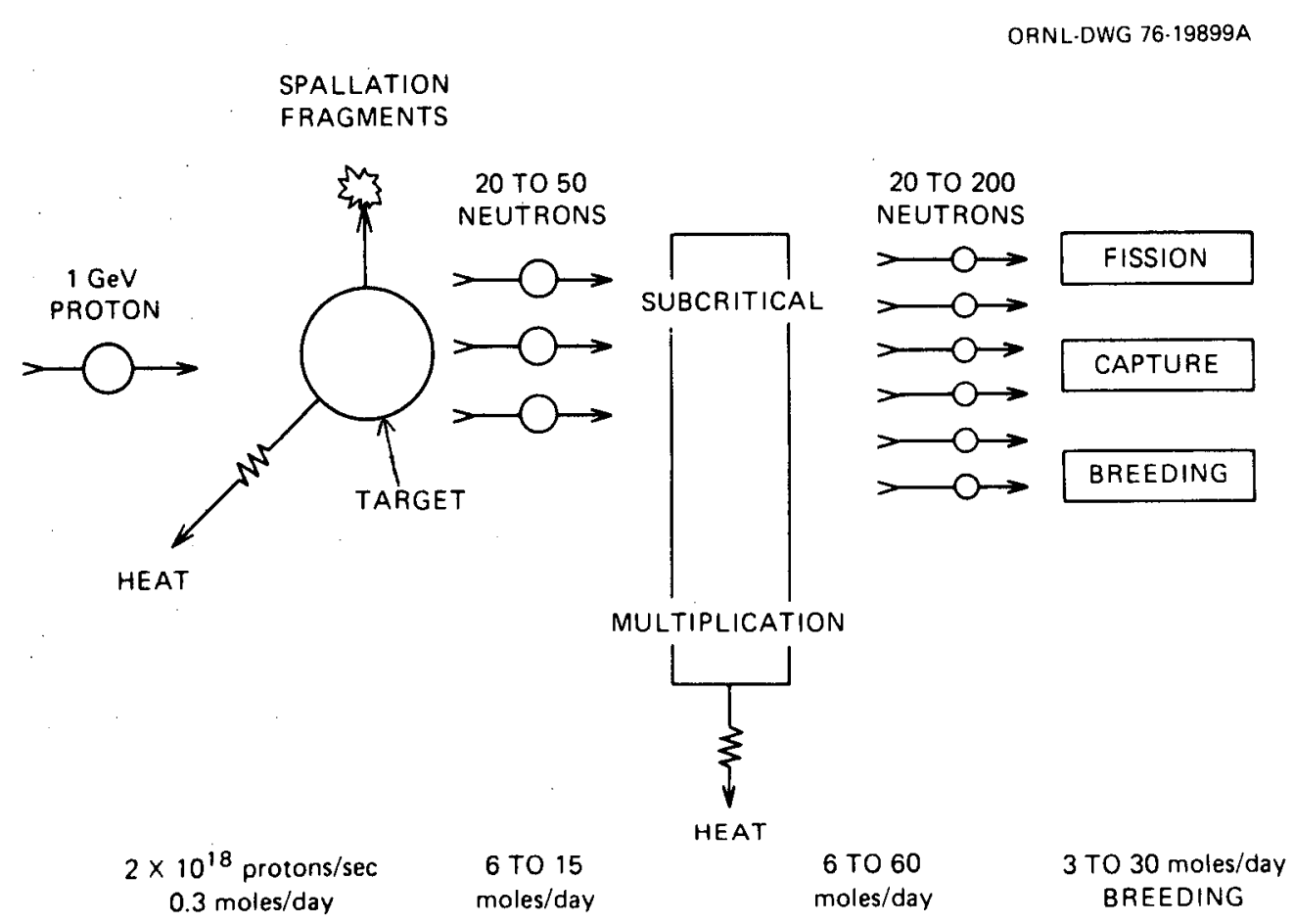

Fig. 1. Schematic of accelerator breeding process.

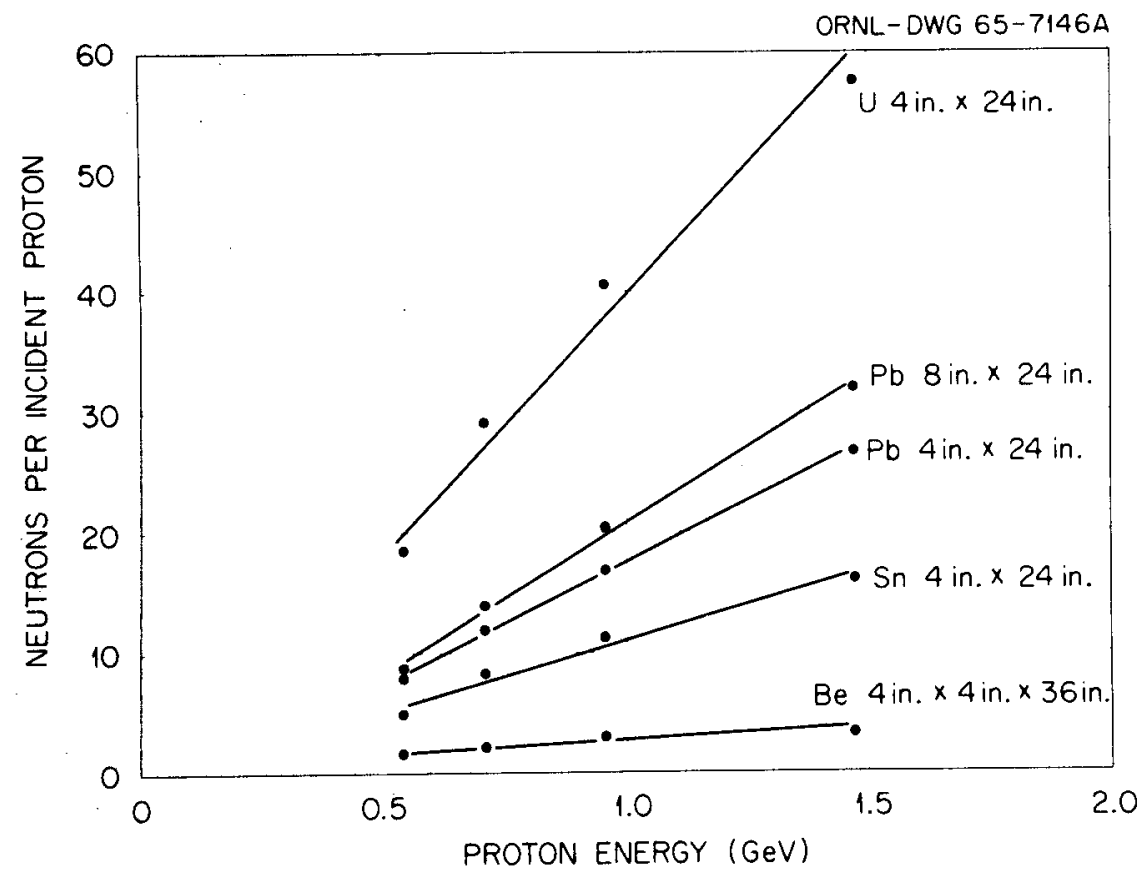

Fig. 2. Neutron yield as a function of target material and proton energy. 


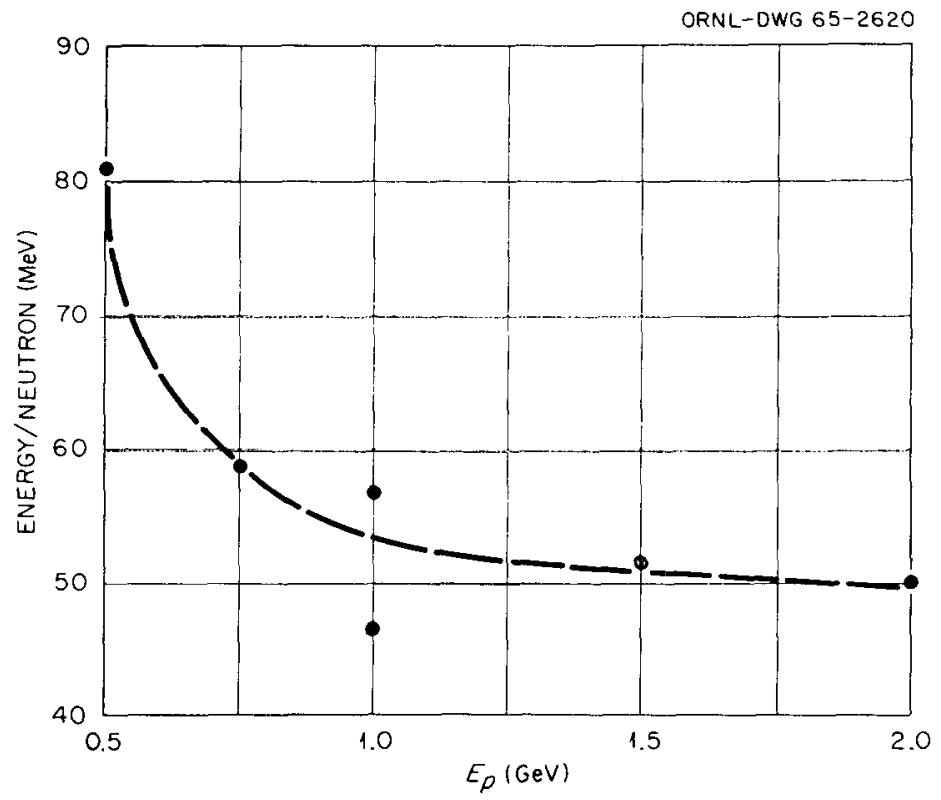

Fig. 3. Energy required to liberate low-energy neutrons by high-energy proton bombardment of $\mathbf{P b}$ target.

Los Alamos Meson Physics Facility (LAMPF), an $800-\mathrm{MeV}$ proton accelerator, has a high output energy at a fraction of the desired beam current, while the machine at the Fermi National Accelerator Laboratory has a low output energy but a high pulsed beam current. On the other hand, it is generally felt that the technology required to attain the needed operating characteristics will require no more than modest extensions of existing technology. The principal areas of concern will be in minimizing beam losses and capital cost and maximizing availability.

The reference accelerator concept used for the TMF-ENFP was derived from the Intense Neutron Generator ${ }^{9}$ (ING) design developed in the 1960s by the AECL (Atomic Energy of Canada Limited) at its Chalk River National Laboratory. Depicted schematically in Fig. 4, the reference accelerator has the following principal components:

1. An ion source and high voltage d.c. injector.

2. Several sections of Alvarez (drift tube) accelerators to accelerate protons in the low-velocity range up to approximately $150 \mathrm{MeV}$.

3. A high-velocity coupled-cavity linear accelerator to increase the proton energy from $150 \mathrm{MeV}$ to the final energy of $1100 \mathrm{MeV}$.

The details of the reference accelerator concept (i.e., the ING concept) and its associated technology development requirements are presented in Ref. 9 and will not be repeated in this report. 


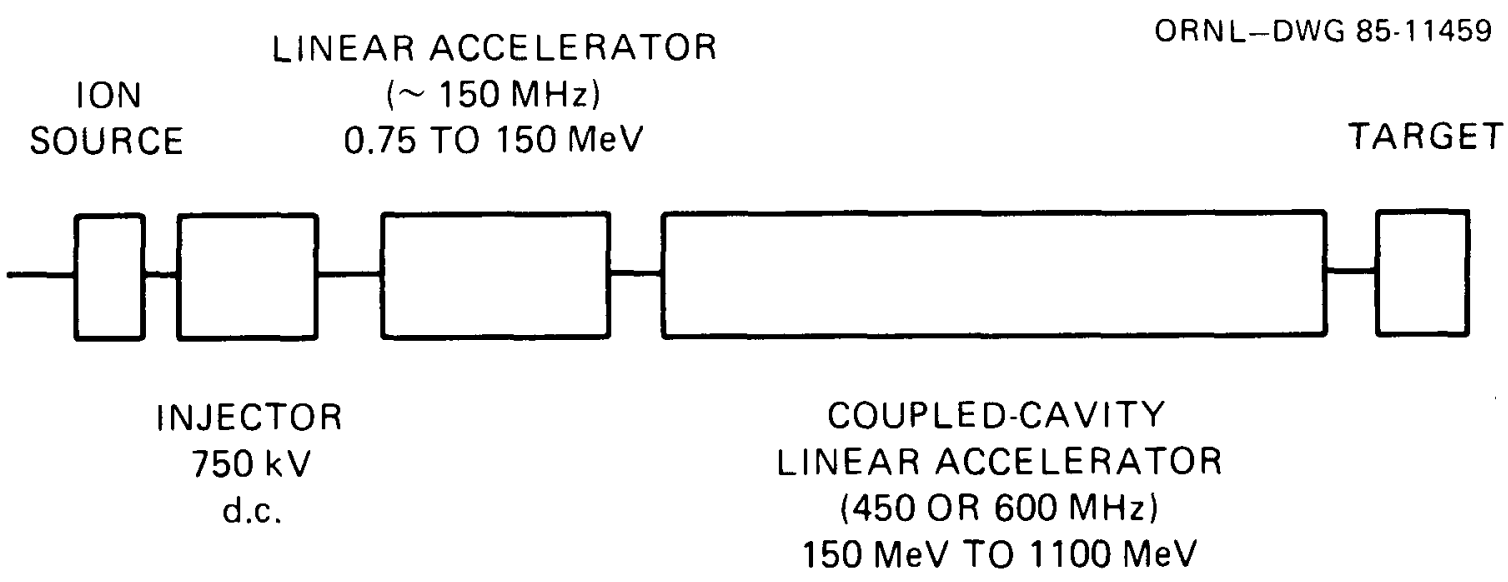

CHARACTERISTICS

$\begin{array}{ll}\text { VOLTAGE GAIN: } & 1.1 \mathrm{MeV} / \mathrm{m} \\ \text { LENGTH: } & 1000 \mathrm{~m} \\ \text { BEAM CURRENT: } & 300 \mathrm{~mA} \text { CONTINUOUS } \\ \text { RF POWER } & 330 \mathrm{MW} \\ \text { CAVITIES } \quad 30 \mathrm{MW} & \\ \text { BEAM } \quad 300 \mathrm{MW} & \\ \text { RF EFFICIENCY: } & 50 \% \\ \text { INPUT POWER } & \sim 660 \mathrm{MW}\end{array}$

Fig. 4. Schematic diagram and outline characteristics of reference accelerator concept.

\subsection{THE REFERENCE TARGET/BLANKET DESIGN}

In preliminary conceptual design analyses, the first objective is to establish the design criteria, which are then used to analyze the various concepts with respect to performance. Since the design proposed by Burns et al. ${ }^{18}$ was considered the most promising among the ORNL studies and since the basic operating characteristics of that design were retained for this study, the same design criteria used for it $^{18}$ and for the earlier analyses ${ }^{16}$ were adopted for the current study.

The design criteria were heavily influenced by the political/economical climate encompassing the commercial power industry in the mid-1970s. In considering this, Mynatt et $a l .{ }^{16}$ identified four major concerns:

1. The threat of nuclear proliferation.

2. The need to isolate or eliminate long-lived nuclear waste.

3. The potential accident risks associated with the Liquid Metal Fast Breeder Reactor and the Gas Cooled Fast Breeder Reactor. 
4. The shortage of known high-grade uranium ores and the uncertain social, environmental, and economic problems associated with mining the more plentiful low-grade uranium ores.

Thus the criteria specified for the original TMF-ENFP were that each of these concerns be minimized.

\subsubsection{The Original TMF-ENFP Design}

The original TMF-ENFP target/blanket design ${ }^{18}$ is depicted schematically in Fig. 5, with the corresponding design parameters presented in Table 1 . The system contains a central flowing column of liquid sodium functioning both as the target for the incident proton beam and as the system coolant.* The sodium target is surrounded by a two-zone multiplier region containing sodium-cooled ternary metal fuel $\left({ }^{239} \mathrm{Pu},{ }^{238} \mathrm{U}\right.$, and $\left.{ }^{232} \mathrm{Th}\right)$, and the multiplier region, in turn, is surrounded by a sodium-cooled thorium metal blanket region. The outer zone of the multiplier region has a lower ${ }^{239} \mathrm{Pu}$ content to flatten the otherwise steep radial gradient of the neutron flux. Both the ternary metal fuel in the multiplier region and the thorium in the blanket are designed as fuel pins, and a vanadium-titanium steel alloy which has excellent metallurgical and neutronic properties is used as the cladding.

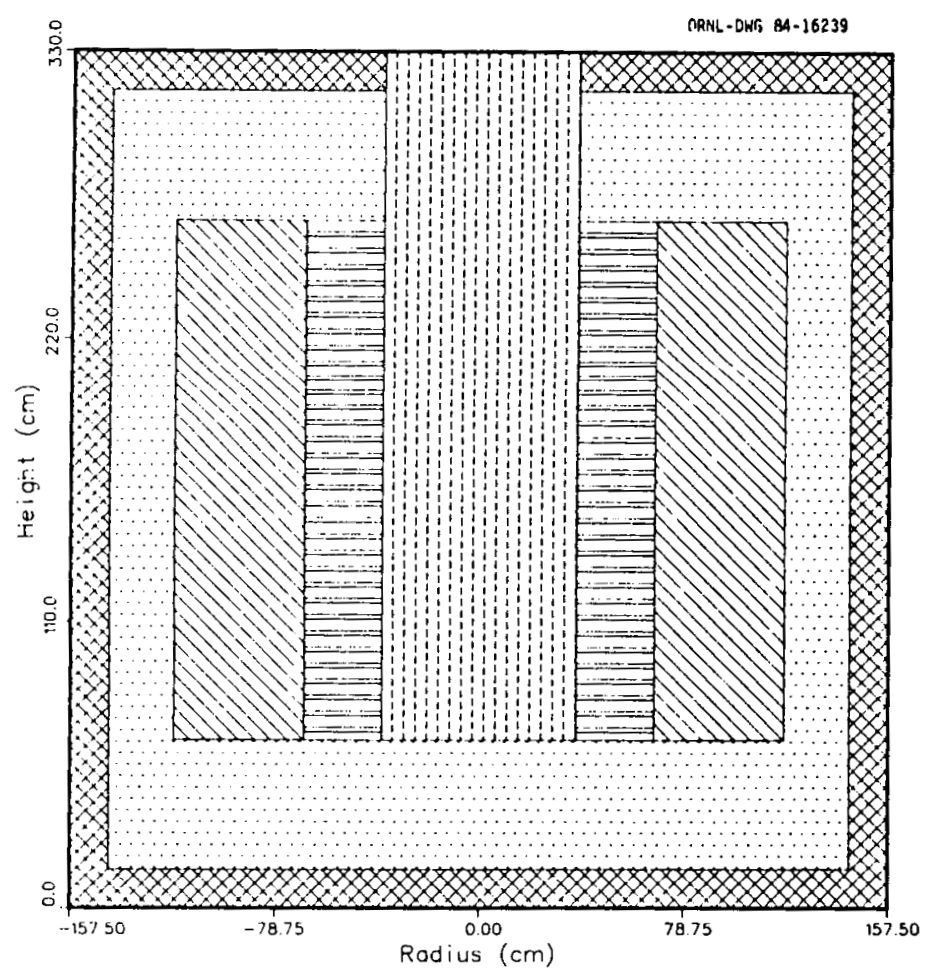

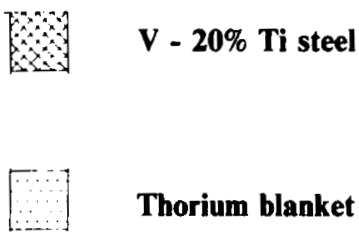

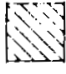

$10 \% \mathrm{Pu}, 12 \% \mathrm{U}, 78 \% \mathrm{Th}$ ternary metal multiplier

7\% Pu, $15 \% \mathrm{U}, 78 \%$ Th ternary metal multiplier

Liquid sodium target

Fig. 5. Schematic diagram of the original TMF-ENFP.

*As noted in Ref, 18, the selection of liquid sodium as the target was dictated by cooling requirements and a number of disadvantages associated with the use of a solid target material. 
Table 1. Original TMF-ENFP design parameters

\begin{tabular}{ll}
$\begin{array}{l}\text { Target: } \\
\text { Composition }\end{array}$ & Liquid sodium \\
Multiplier region: & \\
Composition & Ternary metal \\
Pin outside diameter $(\mathrm{cm})$ & 0.635 \\
Clad thickness $(\mathrm{cm})$ & 0.038 \\
Rod gap & 0.0083 \\
Spacers & Grid \\
Pins/assembly & 271 \\
Pitch diameter $(\mathrm{cm})$ & 3.38 \\
Clad material & V $-20 \%$ Ti steel \\
Coolant material & Sodium \\
Structure material & V $-20 \%$ Ti steel \\
Length $(\mathrm{cm})$ & 200.0 \\
$V_{\text {Fuel }} / V_{\text {Coolant }} / V_{\text {Structure }}$ & $0.35 / 0.50 / 0.15$ \\
Radial blanket region: & \\
Composition & Thorium metal \\
Pin outside diameter $(\mathrm{cm})$ & 1.23 \\
Clad thickness $(\mathrm{cm})$ & 0.038 \\
Rod gap $(\mathrm{cm})$ & 0.0083 \\
Spacers & Grid \\
Pins/assembly & 91 \\
Pitch diameter $(\mathrm{cm})$ & 2.95 \\
Clad material & V $-20 \%$ Ti steel \\
Coolant material & Sodium \\
Structure material & V $-20 \%$ Ti steel \\
Length $(\mathrm{cm})$ & 300.0 \\
$V_{\text {Fuel }} / V_{\text {Coolant }} / V_{\text {Structure }}$ & $0.57 / 0.30 / 0.13$ \\
\hline
\end{tabular}

${ }^{a} \mathrm{Th}, \mathrm{U}$, and $\mathrm{Pu}$; see percentages in Fig. 5 .

The TMF-ENFP was designed to sacrificially burn the ${ }^{239} \mathrm{Pu}$ in a subcritical mode to produce ${ }^{233} \mathrm{U}$ at a rate that is a factor of 2 greater than that from a reactor of the same thermal power rating. Towards this end, the use of a thorium-based alloy $(>78 \% \mathrm{Th})$ has shown excellent performance characteristics, especially in sustaining very high power densities while maintaining reasonable centerline temperatures. The irradiation behavior of the thorium-based ternary metal alloys is considered in Refs. 20-21.

The TMF-ENFP was also designed to extract and utilize the heat generated within the system to make the TMF-ENFP self-sufficient in terms of its own energy balance. Alternatively, the heat could be extracted for process heat applications. 
As designed, the TMF-ENFP met all four of the design criteria outlined above. First, it would reduce the threat of nuclear proliferation because its fuel was intended for use in a proliferation-resistant denatured ${ }^{233} \mathrm{U}$ fuel cycle that was under study in the 1970s. Second, it would reduce the inventory of long-lived plutonium by burning ${ }^{239} \mathrm{Pu}$ to produce ${ }^{233} \mathrm{U}$. Third, its operation in a subcritical mode would reduce the probability of accidents. And fourth, the negative environmental impact of mining large quantities of low-grade uranium ore to obtain a relatively small percentage $(0.7 \%)$ of usable fuel $\left({ }^{235} \mathrm{U}\right)$ would be essentially eliminated.

A summary of the TMF-ENFP nuclear and thermal-hydraulic performance parameters calculated by Burns et al. is presented in Table 2. As shown, the blanket exhibited a nominal increase in system $k_{\text {eff }}$ over the cycle length (from 0.84 to 0.88 ) with the blanket remaining substantially subcritical. The increase in $k_{\text {eff }}$ corresponded to a $30 \%$ increase in blanket multiplication. The blanket averaged a net production of $2.9 \mathrm{~kg}$ of fissile fuel per full power day $\left(5.8 \mathrm{~kg} / \mathrm{FPD}{ }^{233} \mathrm{U}\right.$ produced less a net of $2.9 \mathrm{~kg} / \mathrm{FPD}{ }^{239} \mathrm{Pu}$ burned) over a 90-day residence time. It also generated a substantial amount of thermal power, which could be recovered and converted to electricity to drive the accelerator.

Table 2. Summary of original TMF-ENFP neutronic and thermal-hydraulic performance parameters

$\begin{array}{ll}\text { Nuclear: } & \\ k_{\text {eff }}-\text { BOC } & 0.84 \\ k_{\text {eff }} \text { EOC } & 0.88 \\ \text { Multiplication - BOC } & 6.3 \\ \text { Multiplication - EOC } & 8.3 \\ { }^{233} \mathrm{U} \text { production rate } & 5.8 \mathrm{~kg} / \mathrm{FPD} \\ { }^{239} \mathrm{Pu} \text { net destruction rate } & 2.9 \mathrm{~kg} / \mathrm{FPD} \\ \text { Fissile loading } & 3400 \mathrm{~kg} \\ \text { Residence time } & 90 \mathrm{FPD} \\ \text { Average burnup [inner] } & 17 \mathrm{MWd} / \mathrm{kg} \\ \text { Average burnup [outer] } & 9 \mathrm{MWd} / \mathrm{kg} \\ & \\ \text { Thermal Hydraulic: } & 3300 \mathrm{MW}(\mathrm{t}) \\ \text { Thermal power - BOC } & 4500 \mathrm{MW}(\mathrm{t}) \\ \text { Thermal power - EOC } & 327^{\circ} \mathrm{C} \\ \text { Na inlet temperature } & 535^{\circ} \mathrm{C} \\ \text { Maximum Na outlet temperature } & 914 \mathrm{~cm} / \mathrm{sec} \\ \text { Na velocity } & 750^{\circ} \mathrm{C} \\ \text { Peak centerline temperature } & 700^{\circ} \mathrm{C} \\ \text { Peak cladding temperature } & 1100 \mathrm{~W} / \mathrm{cm}^{3} \\ \text { Maximum smear power density } & 3150 \mathrm{~W} / \mathrm{cm}^{3} \\ \text { Maximum radial power density } & \end{array}$


While this design appears exceptional, it is limited in nuclear performance - not so much by target/blanket technology as by accelerator beam technology. At the time the original TMF-ENFP design was conceived, the reference accelerator beam profile required that the full $300-\mathrm{mA} 1100-\mathrm{MeV}$ proton beam be deposited onto a target area approximately 6 to $10 \mathrm{~cm}$ in diameter. This produced several thermal-hydraulic and material problems which had to be circumvented in the target/blanket design. For example, it mandated the flowing column of liquid sodium as the target. Furthermore, this accelerator beam design limited the potential fuel production since the spallation process was confined to a relatively small area and the ternary metal fuel could not reside directly in the beam.

\subsubsection{The Modified TMF-ENFP Design}

Following the 1979 study, it became possible for the accelerator beam to be spread and/or swept over a larger target area, thereby reducing the material and heat dissipation problems which had to be overcome in the original TMF-ENFP design. Furthermore, a spread and/or swept proton beam design would extend the spallation process over a much wider area and, subsequently, enhance fuel production. Therefore, a modified TMF-ENFP was proposed.

The new design is shown schematically in Fig. 6, with the corresponding design parameters given in Table 3. The principal design changes involved first utilizing the cosinesquared distribution of the incident proton beam shown in Fig. 7. It spread from a 6-cm diameter initial bore to a $200-\mathrm{cm}$ radius at the target/blanket first wall. Second, an Erlenmeyer flask shape was adopted for the fuel and blanket regions to accommodate the modified beam structure and to mitigate leakage of backscattered neutrons. Because of the new spread beam design, the multiplier region was designed to also act as the target. The thorium metal blanket was again placed around the multiplier region, and an additional graphite reflector was employed outside the thorium blanket region to further reduce leakage and increase thermal capture in the blanket. Finally, lead and high-density concrete shields were incorporated to reduce the radiation levels outside the device.

Because the new Erlenmeyer flask design was incompatible with a structured fuel lattice containing fuel pins or elements, the fuel design was changed from fuel pins to metal fuel spheres. This type of fuel has the added advantage of more surface area for heat dissipation, more even burnup over cycle length, and simplified fuel loading/reloading processes. The ternary metal fuel concentrations were also adjusted to ensure a subcritical system over cycle length. In addition, the new design assumed that the fuel spheres would be clad by a vapor deposition process ${ }^{22}$ that would prevent the fission products from entering the sodium coolant, protect the fuel from embrittling or corrosive attack by the coolant, and minimize diffusion and decomposition of the fuel itself at high temperature during irradiation. 


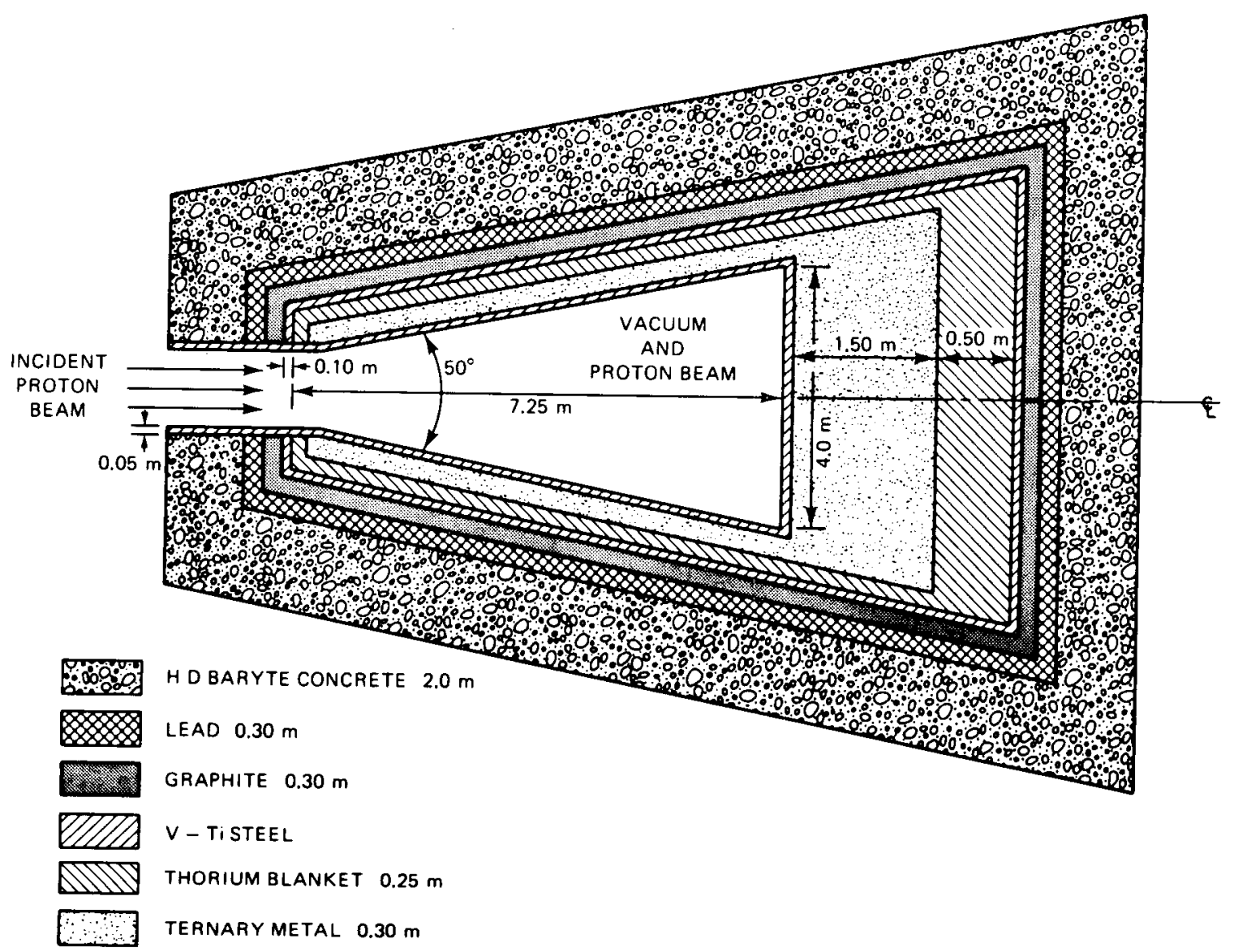

Fig. 6. Schematic diagram of the modified TMF-ENFP. 
Table 3. Modified TMF-ENFP design parameters

Target/multiplier region:

Composition

Sphere outside diameter $(\mathrm{cm})$

Clad material

Clad thickness $(\mathrm{cm})$

Coolant material

Structure material

$V_{\text {Fuel }} / V_{\text {Coolant }} / V_{\text {Structure }}$

Ternary metal ( $78 \%$ Th, $19 \% \mathrm{U}, 3 \% \mathrm{Pu})$

2.0

Nickel

$2.0 \times 10^{-4}$ (nominal)

Sodium

V - 20\% Ti steel

$0.5236 / 0.4264 / 0.05$

Radial blanket region:

Composition

Thorium metal

Sphere outside diameter $(\mathrm{cm})$

2.0

Clad material

Nickel

Clad thickness

Coolant material

$2.0 \times 10^{-4}$ (nominal)

Sodium

Structure material

V - 20\% Ti steel

$V_{\text {Fuel }} / V_{\text {Coolant }} / V_{\text {Structure }}$

$0.5236 / 0.4264 / 0.05$

\section{Reflector region:}

Composition

Graphite

DRNL - DNG 84-16241

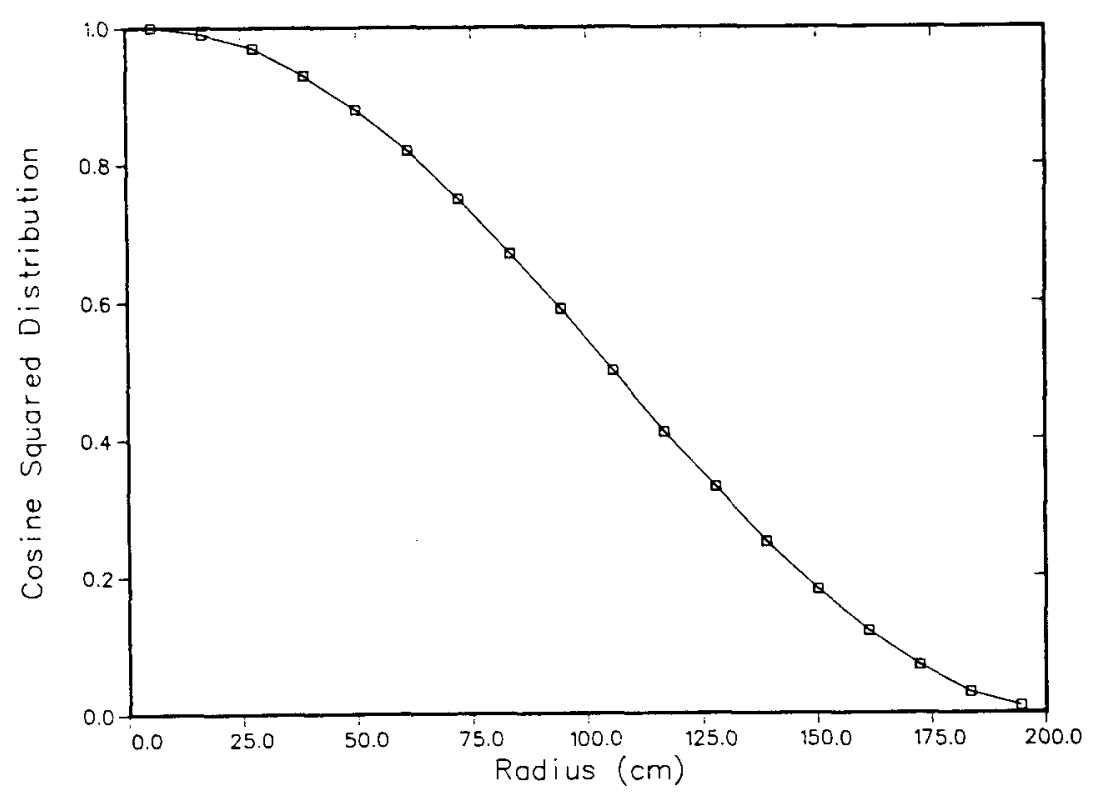

Fig. 7. Profile of proton beam incident on the target/blanket first wall. 


\section{ANALYSIS METHODS AND CODES}

The objectives of this investigation were accomplished through the computational strategy presented in Fig. 8. The basic strategy was comprised of three major steps: (1) cross-section processing and mixing, (2) a two-dimensional analysis of the reference design, and (3) a one-dimensional parameter optimization analysis. In addition, a high-energy transport calculation was performed to define the neutron source and quantify the heat deposition by high-energy particles.

\subsection{CROSS-SECTION PROCESSING AND MIXING}

The cross-section data base utilized in the two-dimensional and the one-dimensional (optimization) analyses was the 174-neutron-group, 38-gamma-group VITAMIN-E master library ${ }^{23}$ derived from ENDF/B-V data. The number of cross-section groups actually used in the calculations was reduced by processing the $174 n-38 \gamma$ library with AMPX-II, ${ }^{24}$ a modular code system for generating coupled multigroup neutron-gamma-ray cross-section libraries from ENDF data.

As shown by the cross-section processing and mixing flow path in Fig. 8, two final group structures were chosen. A self-shielded $1 / E$-weighted coupled $36 n-23 \gamma$ library was used in the two-dimensional transport analysis of the modified reference design, while a region-weighted $3 n$ library, collapsed from the $36 n-23 \gamma$ library via transport theory, was used in the one-dimensional parameter optimization analysis. The upper energy group boundaries for both libraries are presented in Table 4.

The resonance self-shielding of the 174 neutron groups was performed with the BONAMI ${ }^{24}$ module (which uses the Bondarenko method) with appropriate blanket zones modeled as infinite homogeneous regions. The actual collapsing of the $174 n-38 \gamma$ crosssection group structure into the resultant $36 n-23 \gamma$ structure was performed with the collapsing module MALOCS. ${ }^{24}$ A $1 / E$ weighting spectrum was used since it best described the dominant slowing-down mechanism present in the target/blanket. The final processing of the $36 n-23 \gamma$ cross-section library into ANISN/DOT-formatted mixtures was performed with $\mathrm{AXMIX}^{25}$ for the appropriate material compositions, properties, and atom densities (see Table 5).

The final $3 n$ library necessary for the parameter optimization analysis was obtained with the XSDRNPM ${ }^{24}$ module, a one-dimensional discrete ordinates transport code for spatial weighting. A separate library was generated for eight different ternary metal fuel compositions used in the optimization study (see Table 6). The final processing of the $3 n$ cross-section library into a ORIGEN-formatted library was performed with COUPLE. ${ }^{26}$

\subsection{TWO-DIMENSIONAL TRANSPORT ANALYSIS}

The two-dimensional transport analysis of the modified TMF-ENFP reference target/blanket design was performed with DOT 4.3, a one- and two-dimensional neutron/photon discrete ordinates transport code. ${ }^{27}$ The system was modeled in cylindrical geometry as shown in Fig. 9, and a $P_{3}$ scattering approximation and an $S_{6}$ angular quadrature set were employed. 


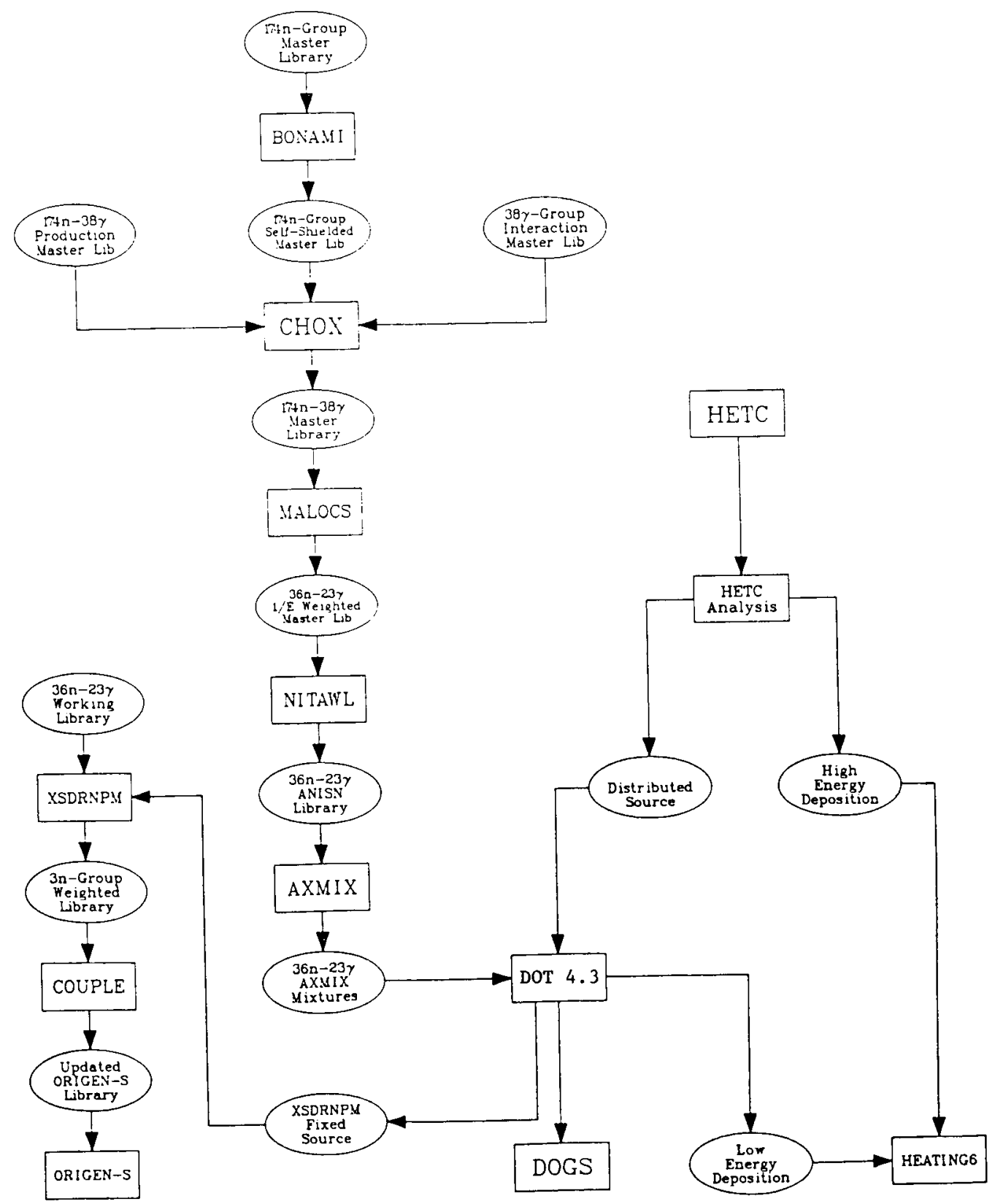

Fig. 8. Computational flow diagram for the neutronics and thermal-hydraulic analyses. 
Table 4. Coupled $36 n-23 \gamma$ group structure and $3 n$ group structure

\begin{tabular}{|c|c|c|c|c|}
\hline \multicolumn{2}{|c|}{ Neutron group number } & \multirow{2}{*}{$\begin{array}{c}\text { Neutron } \\
\text { upper energy } \\
\text { boundaries } \\
(\mathrm{eV})\end{array}$} & \multirow{2}{*}{$\begin{array}{c}\text { Gamma-ray } \\
\text { group } \\
\text { number }\end{array}$} & \multirow{2}{*}{$\begin{array}{c}\text { Gamma-ray } \\
\text { upper energy } \\
\text { boundaries } \\
(\mathrm{eV})\end{array}$} \\
\hline 36 group & 3 group & & & \\
\hline 1 & \multirow[t]{16}{*}{1} & $1.9640+07$ & 1 & $2.00+07$ \\
\hline 2 & & $1.4918+07$ & 2 & $1.20+07$ \\
\hline 3 & & $1.3499+07$ & 3 & $1.00+07$ \\
\hline 4 & & $1.2214+07$ & 4 & $8.00+06$ \\
\hline 5 & & $1.0000+07$ & 5 & $7.50+06$ \\
\hline 6 & & $8.1873+06$ & 6 & $7.00+06$ \\
\hline 7 & & $6.7032+06$ & 7 & $6.50+06$ \\
\hline 8 & & $5.4881+06$ & 8 & $6.00+06$ \\
\hline 9 & & $4.4933+06$ & 9 & $5.50+06$ \\
\hline 10 & & $3.6788+06$ & 10 & $5.00+06$ \\
\hline 11 & & $3.0119+06$ & 11 & $4.50+06$ \\
\hline 12 & & $2.4660+06$ & 12 & $4.00+06$ \\
\hline 13 & & $2.0190+06$ & 13 & $3.50+06$ \\
\hline 14 & & $1.6530+06$ & 14 & $3.00+06$ \\
\hline 15 & & $1.3534+06$ & 15 & $2.50+06$ \\
\hline 16 & & $1.1080+06$ & 16 & $2.00+06$ \\
\hline 17 & \multirow[t]{19}{*}{2} & $9.0718+05$ & 17 & $1.50+06$ \\
\hline 18 & & $7.4274+05$ & 18 & $1.00+06$ \\
\hline 19 & & $4.9787+05$ & 19 & $7.00+05$ \\
\hline 20 & & $3.3373+05$ & 20 & $4.00+05$ \\
\hline 21 & & $2.2371+05$ & 21 & $2.00+05$ \\
\hline 22 & & $1.4996+05$ & 22 & $1.00+05$ \\
\hline 23 & & $8.6517+04$ & 23 & $6.00+04$ \\
\hline 24 & & $3.1828+04$ & & $1.00+04^{a}$ \\
\hline 25 & & $1.5034+04$ & & \\
\hline 26 & & $7.1017+03$ & & \\
\hline 27 & & $3.3546+03$ & & \\
\hline 28 & & $1.5846+03$ & & \\
\hline 29 & & $4.5400+02$ & & \\
\hline 30 & & $1.0130+02$ & & \\
\hline 31 & & $2.2603+01$ & & \\
\hline 32 & & $1.0667+01$ & & \\
\hline 33 & & $5.0435+00$ & & \\
\hline 34 & & $2.3824+00$ & & \\
\hline 35 & & $1.1253+00$ & & \\
\hline \multirow[t]{2}{*}{36} & 3 & $4.1399-01$ & & \\
\hline & & $1.0000-05^{a}$ & & \\
\hline
\end{tabular}

${ }^{a}$ Lower energy boundary of last group. 
Table 5. Material compositions used in radiation transport analysis

Density

Material

Element

(atoms $/ \mathrm{b}-\mathrm{cm}$ )

1. Ternary metal fuel

(78\% Th, 19\% U, 3\% Pu)

at $12.50 \mathrm{~g} / \mathrm{cc}$

${ }^{232} \mathrm{Th}$
${ }^{235} \mathrm{U}$
${ }^{238} \mathrm{U}$
${ }^{239} \mathrm{Pu}$

$2.5300-02$

4.2603-05

$5.9672-03$

$9.4486-04$

2. Thorium metal fuel

${ }^{232} \mathrm{Th}$

$3.0360-02$ at $11.7 \mathrm{~g} / \mathrm{cc}$

3. Sodium (liquid)

Sodium

$2.1739-02$ at $0.83 \mathrm{~g} / \mathrm{cc}$

4. Graphite at $2.26 \mathrm{~g} / \mathrm{cc}$

Carbon

$1.1334-01$

5. Lead

Lead

$3.3138-02$

at $11.4 \mathrm{~g} / \mathrm{cc}$

6. V $-20 \%$ Ti steel at $5.782 \mathrm{~g} / \mathrm{cc}$

Vanadium

5.4683-02

Titanium

$1.4541-02$

7. Nickel clad

Nickel

$9.1387-02$ at $8.9 \mathrm{~g} / \mathrm{cc}$

8. HD barytes concrete at $3.49 \mathrm{~g} / \mathrm{cc}$

$\begin{array}{ll}\text { Barium } & 6.4459-03 \\ \text { Oxygen } & 4.1033-02 \\ \text { Sulfur } & 6.5360-03 \\ \text { Iron } & 3.3109-03 \\ \text { Calcium } & 2.3895-03 \\ \text { Silicon } & 1.3094-03 \\ \text { Aluminum } & 4.4666-04 \\ \text { Hydrogen } & 9.0348-03 \\ \text { Magnesium } & 3.2197-04 \\ \text { Sodium } & 1.3094-04 \\ \text { Manganese } & 3.2896-05\end{array}$


Table 6. Material composition of the ternary metal fuel as a function of fissile enrichment

\begin{tabular}{|c|c|c|c|c|c|c|}
\hline \multicolumn{3}{|c|}{ Percent Composition } & \multicolumn{4}{|c|}{$\left(\right.$ atoms $\left.\cdot \mathrm{b}^{-1} \cdot \mathrm{cm}^{-1}\right)$} \\
\hline Th & $\mathrm{U}$ & $\mathrm{Pu}$ & ${ }^{232} \mathrm{Th}$ & ${ }^{235} \mathrm{U}$ & ${ }^{238} \mathrm{U}$ & ${ }^{239} \mathrm{Pu}$ \\
\hline 78 & 22 & 0 & $2.5300-02$ & $4.9330-05$ & $6.9094-03$ & 0 \\
\hline 78 & 21 & 1 & $2.5300-02$ & $4.7088-05$ & $6.5953-03$ & $3.1495-04$ \\
\hline 78 & 20 & 2 & $2.5300-02$ & $4.4845-05$ & $6.2813-03$ & $6.2991-04$ \\
\hline 78 & 19 & 3 & $2.5300-02$ & $4.2603-05$ & $5.9672-03$ & $9.4486-04$ \\
\hline 78 & 18 & 4 & $2.5300-02$ & $4.0361-05$ & $5.6532-03$ & $1.2598-03$ \\
\hline 78 & 17 & 5 & $2.5300-02$ & $3.8119-05$ & $5.3391-03$ & $1.5748-03$ \\
\hline 78 & 16 & 6 & $2.5300-02$ & $3.5876-06$ & $5.0250-03$ & $1.8897-03$ \\
\hline 78 & 15 & 7 & $2.5300-02$ & $3.3634-05$ & $4.7110-03$ & $2.2047-03$ \\
\hline
\end{tabular}

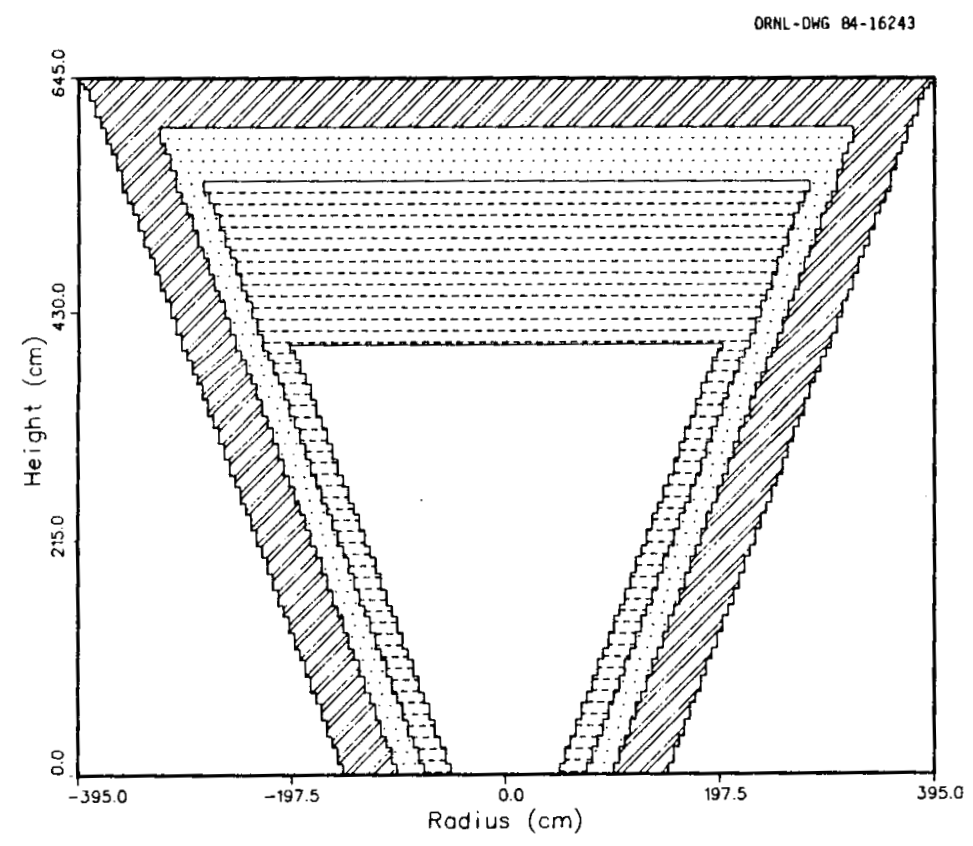

Thorium blanket

3\% Pu, 19\% U, 78\% Th ternary metal multiplier

Graphite

Fig. 9. Two-dimensional DOT-4.3 model for the modified TMF-ENFP target/blanket. 
Preliminary to the two-dimensional analysis, the transport of the high-energy proton beam was calculated with HETC, ${ }^{28}$ a code designed to study the transport of high- and medium-energy nucleons and pions through matter. HETC modeled the profile of the $1100-\mathrm{MeV}$ proton beam incident on the target/blanket wall and followed the subsequent intranuclear-cascade process. The secondary neutrons produced with energies $\leqslant 20 \mathrm{MeV}$ were then used as the source for the two-dimensional DOT-4.3 calculation. The cumulative distribution function of the incident proton beam distribution, which HETC sampled, is depicted graphically in Fig. 10.

In addition to yielding the neutron source, HETC also calculated the transport and deposition of charged particles (protons and charged pions) and of neutrons with energies greater than $20 \mathrm{MeV}$. These results were analyzed (see Fig. 8) to obtain the spatial distribution of the high-energy deposition for the subsequent heat-transfer and thermalhydraulic analysis.

The HETC spatial distribution of the low-energy $(<20 \mathrm{MeV})$ neutrons was used as a fixed source with fission. The resulting spatial distributions of the neutron and gamma-ray flux spectra calculated by DOT 4.3 were extensively utilized in DOGS, ${ }^{29}$ a collection of graphics programs for support of discrete ordinates codes, to measure the nuclear performance of the modified TMF-ENFP reference target/blanket design. In addition, the spatial distributions of the low-energy deposition data from DOT 4.3 were utilized, together with the high-energy deposition data from HETC, in HEATING $6^{30}$ to calculate the heattransfer and thermal-hydraulic performance of the modified TMF-ENFP.

\subsection{ONE-DIMENSIONAL PARAMETER OPTIMIZATION ANALYSIS}

The one-dimensional parameter optimization study was performed to determine the impact of design changes on both the neutronic characteristics and the thermal-hydraulic characteristics of the modified TMF-ENFP reference target/blanket design. The principal tools used in the neutronic parameter analysis were the isotope generation and depletion code ORIGEN-S $\mathrm{S}^{31}$ and the $3 n$ libraries generated in COUPLE. The thermal-hydraulic parameter studies were performed with HEATING6. The DOT-4.3 spatially averaged flux spectrum for each zone was used as the input source spectra in XSDRNPM to produce the region-weighted $3 n$ libraries for the optimization calculations.

The key neutronic parameters investigated in the optimization studies were (1) the ${ }^{233} \mathrm{U}$ production and ${ }^{239} \mathrm{Pu}$ destruction rates, (2) the ${ }^{232} \mathrm{U}$ and ${ }^{228} \mathrm{Th}$ byproduct production rates, (3) the first-wall DPAs (displacements per atom) and gas production, (4) the thermal power, and (5) the system $k_{\text {eff }}$ and multiplication. These parameters were investigated with respect to irradiation cycle length, reprocessing mode, and initial fissile concentration in the ternary metal fuel (see Table 6).

The principal parameters studied in the heat-transfer and thermal-hydraulic analysis were the temperatures along the fuel centerline and in the first wall. These parameters were analyzed with respect to sodium velocity, metal fuel sphere size, and initial fissile concentration. An empirical correlation for liquid sodium flowing around a heated sphere was used in the fuel sphere heat-transfer analysis. In particular, the correlation is $\mathrm{Nu}=2$ $+0.386(\operatorname{RePr})^{1 / 2}$ for $3.6 \times 10^{4} \leqslant \operatorname{Re} \leqslant 1.6 \times 10^{5}$. 


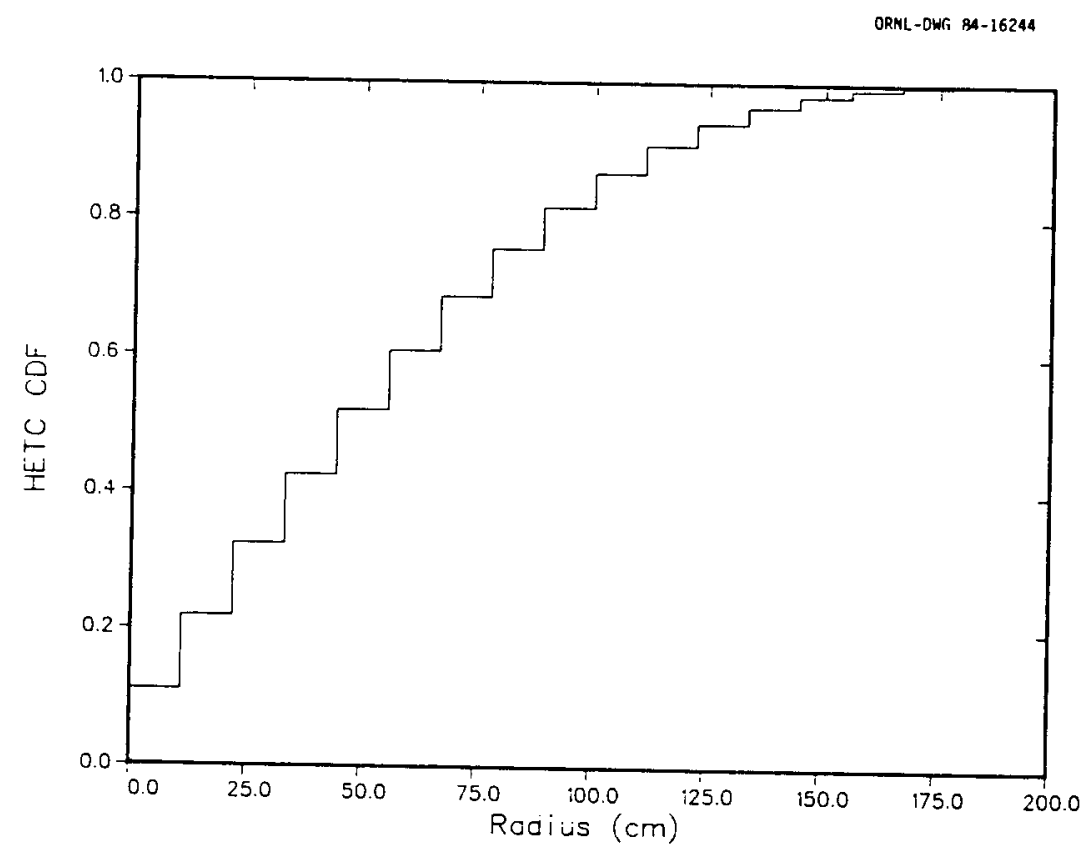
tion.

Fig. 10. HETC cumulative distribution function of the incident proton beam distribu- 


\section{CALCULATIONAL RESULTS}

The results of both the neutronic analysis and the heat-transfer and thermal-hydraulic analysis for the modified TMF-ENFP target/blanket design are presented in this section, including those obtained from the one-dimensional parameter optimization study. Whenever possible, the results are presented in a format suitable for comparison to the original TMF-ENFP target/blanket design.

\subsection{THE HIGH-ENERGY TRANSPORT RESULTS}

As stated previously, the HETC analysis yielded the spatial distribution of neutrons in the modified target/blanket design with energy less than $20 \mathrm{MeV}$, which was required as the source for the DOT-4.3 two-dimensional calculation. Integration of the HETC distributed source over all space resulted in the neutron source spectrum shown in Fig. 11. Further integration over energy yielded a total of 36.4 neutrons per source proton produced in the reference target/blanket assembly. Therefore, for the $300-\mathrm{mA} 1100-\mathrm{MeV}$ proton beam with a corresponding proton density of approximately $2.0 \times 10^{18}$ protons $/ \mathrm{sec}$, the neutron flux density was determined to be approximately $7.3 \times 10^{19}$ neutrons/sec prior to low-energy $(E \leqslant 20 \mathrm{MeV})$ transport, i.e., prior to neutron multiplication in the target/blanket assembly.

The HETC analysis also yielded the fractional distribution of the proton beam energy deposited in the target/blanket by the various spallation particles. Table 7 shows that $80 \%$ of the energy deposition is due to primary and secondary protons. (Note that the energy deposition by low-energy neutron transport and fission is not included in these results.) The total energy deposited by the incident proton beam and the subsequent spallation reactions, i.e., high-energy fission, etc., was determined to be approximately $381 \mathrm{MW}$. This energy is comparable to the power deposited in the liquid sodium target of the original TMF-ENFP; however, the power density is much less due to the spatial distribution of the incident beam.

\subsection{THE TWO-DIMENSIONAL REFERENCE DESIGN RESULTS}

The results of the two-dimensional reference design analysis indicate a substantial gain in neutron efficiency when the spread beam is utilized. A comparison of some of the key performance parameters of the original and modified designs, presented in Table 8, shows that the modified design resulted in a slightly higher net fissile production rate $(3.43$ $\mathrm{kg} / \mathrm{FPD}$ versus $2.90 \mathrm{~kg} / \mathrm{FPD}$ for the original design) for approximately a factor of three decrease in the system $k_{\text {eff }}$. However, with a lower system $k_{\text {eff }}$ and multiplication, the thermal power deposited in the modified target/blanket was over a factor of two less than that deposited in the original design.

Evidence of the neutron efficiency is also apparent from the major reaction rates shown in Table 9 for the beginning-of-cycle (BOC) conditions. DOT-4.3 calculations of the transport of the low-energy ( $E \leqslant 20 \mathrm{MeV}$ ) HETC-calculated neutron source yielded an eventual neutron source of approximately 90.2 neutrons per source proton. The increased 


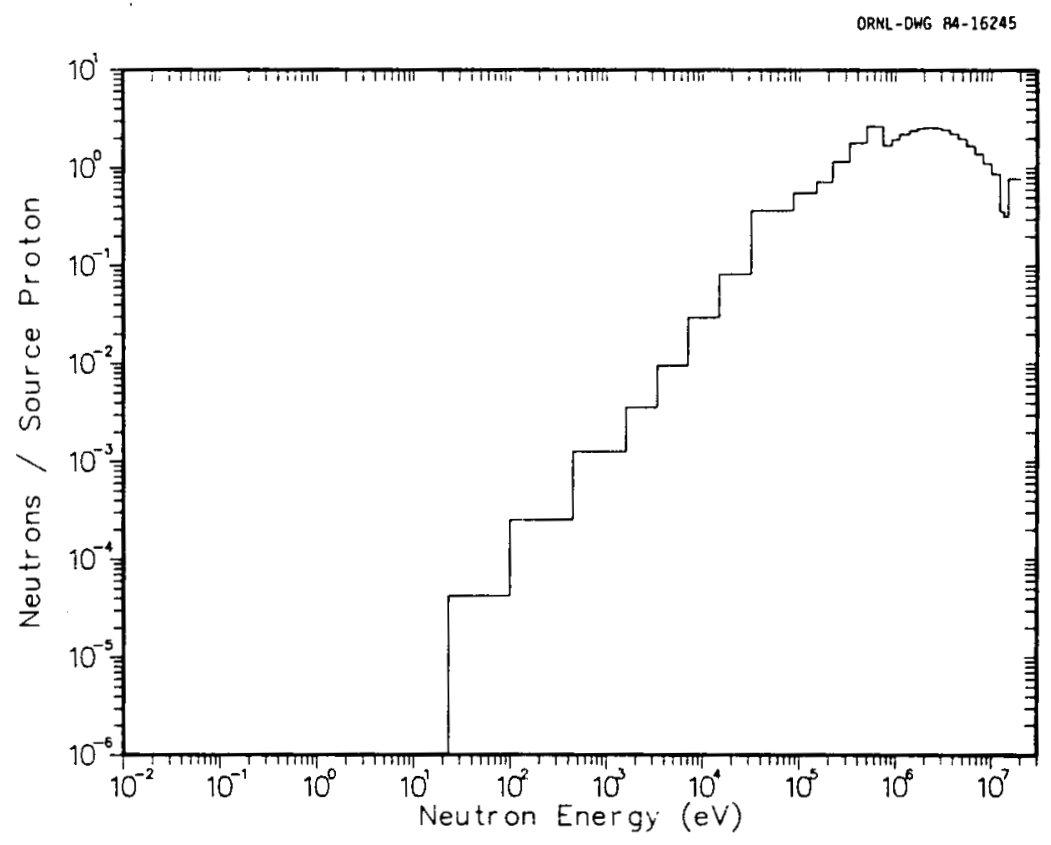

Fig. 11. HETC neutron source spectrum.

Table 7. HETC distribution of the proton beam energy deposited in the target/blanket ${ }^{a}$

${ }^{a}$ Excludes energy deposition from low-energy $(E \leqslant$ $20 \mathrm{MeV}$ ) neutron transport and fission.

${ }^{b}$ Fast fission (includes fission gamma rays and fission product recoil). 
Table 8. Comparison of key performance parameters between the original and modified TMF-ENFP designs

\begin{tabular}{lcc}
\hline \multicolumn{1}{c}{ Parameter } & Original & Modified \\
\hline BOC $k_{\text {eff }}$ & 0.84 & 0.27 \\
BOC multiplication & 6.30 & 1.37 \\
${ }^{233} \mathrm{U}$ production rate, $\mathrm{kg} / \mathrm{FPD}$ & 5.80 & 3.75 \\
${ }^{239} \mathrm{Pu}$ net destruction rate, $\mathrm{kg} / \mathrm{FPD}$ & 2.90 & 0.32 \\
BOC thermal power, $\mathrm{MW}(\mathrm{t})$ & 3300 & 1535 \\
\hline
\end{tabular}

number of neutrons, which originated primarily from $(n, 2 n)$ and $(n, f)$ reactions in the fuel, allowed the primary function of the TMF-ENFP to be realized since a substantial number of the neutrons (56.3) were utilized for ${ }^{233} \mathrm{U}$ production via the ${ }^{232} \mathrm{Th}(n, \gamma)$ reaction. A second result exemplifying the efficient utilization of the neutron source is seen in the other major reaction rates for thorium $(n, 2 n ; n, 3 n$; and $n, f)$. While these reactions destroyed the fertile material, they produced neutrons for other reactions.

Another point of interest in viewing the major reaction rates is the comparison of the ${ }^{239} \mathrm{Pu}$ production and destruction rates. Since a large fraction of the low-energy neutron multiplication is produced from fissions in the ${ }^{239} \mathrm{Pu}$ fuel, it is necessary to maintain an adequate amount of ${ }^{239} \mathrm{Pu}$ for efficient fuel production but without increasing the ${ }^{239} \mathrm{Pu}$ inventory over time. This objective is realized because the ${ }^{239} \mathrm{Pu}$ is being destroyed at a rate of approximately 15 reactions/proton and created (via the ${ }^{238} \mathrm{U}(n, \gamma)$ reaction) at a rate of approximately 10.4 reactions/proton. This results in a slight decrease in the ${ }^{239} \mathrm{Pu}$ inventory over cycle, thereby realizing a second objective of the target/blanket design: to burn ${ }^{239} \mathrm{Pu}$ to produce ${ }^{233} \mathrm{U}$.

A final point of interest is the low parasitic absorption in the cladding and structural components of the modified target/blanket design. Summing all reactions yielded less than two neutrons per source proton absorbed in those components of the target/blanket.

This last point brings up a principal concern of the accelerator breeder reactor not addressed in the original design analysis and only briefly examined in this study, and that is the radiation damage to the first wall separating the proton beam chamber from the target/blanket area. We performed a brief radiation damage analysis for the position in the first wall of the highest neutron/proton fluence $(r=0.0)$ and assumed a $270-\mathrm{FPD} / \mathrm{yr}$ operation. The results yielded a maximum first-wall DPA of approximately 315 , a maximum helium gas production of approximately $240 \mathrm{ppm}$, and a maximum hydrogen gas production of approximately $1390 \mathrm{ppm}$. A review of the literature revealed that acceptable limits for these parameters have not been determined for V-20\% Ti steel; however, if the limits for stainless steel are used as a guide, the analysis indicates that the expected life of the first wall would be limited to approximately 90 days. Since ternary metal fuel is known to have stronger radiation performance characteristics than stainless steel, ${ }^{21}$ the first wall was conservatively limited to 90 days, and no detailed radiation damage study of the fuel was performed. Correspondingly, the fuel residence time was set to be 90 days. 
Table 9. Major reaction rates for the modified TMF-ENFP target/blanket design at beginning of cycle

Thorium reactions

$$
\begin{aligned}
& \operatorname{Th}(n, 2 n) \\
& \operatorname{Th}(n, 3 n) \\
& \operatorname{Th}(n, f) \\
& \operatorname{Th}(n, \gamma)
\end{aligned}
$$

0.3486

2.1714

56.2745

${ }^{235} \mathbf{U}$ reactions

$$
\begin{aligned}
& { }^{235} \mathrm{U}(n, 2 n) \\
& { }^{235} \mathrm{U}(n, f) \\
& { }^{235} \mathrm{U}(n, \gamma)
\end{aligned}
$$

6.5442

0.1396

${ }^{238} \mathrm{U}$ reactions

$$
\begin{aligned}
& { }^{238} \mathrm{U}(n, 2 n) \\
& { }^{238} \mathrm{U}(n, 3 n) \\
& { }^{238} \mathrm{U}(n, f) \\
& { }^{238} \mathrm{U}(n, \gamma)
\end{aligned}
$$

$$
\begin{array}{r}
0.3063 \\
0.0467 \\
1.9407 \\
10.3576
\end{array}
$$

${ }^{239} \mathrm{Pu}$ reactions

$$
\begin{aligned}
& { }^{239} \mathrm{Pu}(n, 2 n) \\
& { }^{239} \mathrm{Pu}(n, 3 n) \\
& { }^{239} \mathrm{Pu}(n, f) \\
& { }^{239} \mathrm{Pu}(n, \gamma)
\end{aligned}
$$

12.6551

2.3696

Non-fuel neutron multiplication reactions

$$
\begin{array}{ll}
\mathrm{Na}(n, 2 n) & 0.0174 \\
\mathrm{Ti}(n, 2 n) & 0.0075 \\
\mathrm{~V}(n, 2 n) & 0.0351 \\
\mathrm{Ni}(n, 2 n) & 0.0001
\end{array}
$$

Parasitic absorption reactions
$\mathrm{Na}(n, \gamma)$
$\operatorname{Ti}(n, \gamma)$
0.3028
$\mathrm{V}(n, \gamma)$
0.1635
$\mathrm{Ni}(n, \gamma)$
0.5183
0.0089
$\mathrm{C}(n, \gamma)$
0.1792
$\mathrm{Na}(n, p)$ and $(n, \alpha)$
0.1412
$\operatorname{Ti}(n, p)$ and $(n, \alpha)$
0.0088
$\mathrm{V}(n, p),(n, d)$ and $(n, \alpha)$
0.0098
$\mathrm{Ni}(n, p)$ and $(n, \alpha)$
$\mathrm{C}(n, d)$ and $(n, \alpha)$
0.0063

Sum 
The final results of the two-dimensional transport analysis of the modified

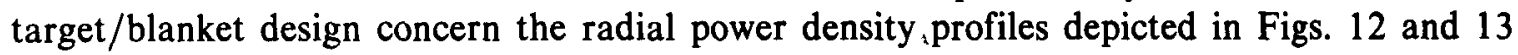
and the axial power density profiles shown in Fig. 14. In general, the radial power density profiles were peaked in the center primarily owing to the cosine-squared distribution of the incident proton beam. The results in Fig. 12 show a peak power density in the first wall of approximately $2.3 \mathrm{~kW} / \mathrm{cm}^{3}$, a peak power density in the sodium next to the first wall of approximately $0.25 \mathrm{~kW} / \mathrm{cm}^{3}$, and a peak power density in the fuel adjacent to the first wall (the "first row" fuel) of approximately $5.8 \mathrm{~kW} / \mathrm{cm}^{3}$. At approximately $10 \mathrm{~cm}$ from the centerline of the target/blanket, the power density in the first wall and sodium has decreased by a factor of 3.5 and the power density in the fuel adjacent to the first wall has decreased by a factor of 2.5 .

The smaller decrease in the fuel power density is due to the added contribution from fission. This result is exemplified further in Fig. 13, which separates the power density profile into the high-energy component calculated by HETC and the low-energy component, principally due to fission, calculated by DOT 4.3. The peak power density in the target/blanket, $6.0 \mathrm{~kW} / \mathrm{cm}^{3}$, occurs approximately $15 \mathrm{~cm}$ from the first wall on the central axis, with the largest fraction due to the high-energy component. Radially outward the low-energy fission component becomes dominant, with the total power density decreasing by a factor of 6 approximately $25 \mathrm{~cm}$ from the centerline of the target/blanket.

The axial power density results (Fig. 14) confirm the peak power density occurring approximately $15 \mathrm{~cm}$ from the first wall along the central axis. These results also show that the high-energy contribution dominates in the first $50 \mathrm{~cm}$ of the target/blanket and then falls off rapidly. Finally, the results show a gradual decrease in the total axial power density in the first 70 to $80 \mathrm{~cm}$ of the target/blanket before a random behavior of the high-energy curve begins. (Note: The random behavior is due to statistics in the HETC calculation.)

\subsection{THE ONE-DIMENSIONAL PARAMETER OPTIMIZATION RESULTS}

The preceding results have shown that the modified TMF-ENFP target/blanket design is a more efficient fissile fuel breeder than the original TMF-ENFP design; however, the base case analyzed did not substantially improve the performance of the target/blanket design with respect to net fissile production, and it actually decreased the performance with respect to thermal power production.

The principal reason for this lack of improvement was due to the choice of the elemental composition of the ternary metal fuel $\left(78 \%{ }^{232} \mathrm{Th}, 19 \% \mathrm{U}, 3 \%{ }^{239} \mathrm{Pu}\right)$ for the modified TMF-ENFP. The composition was chosen primarily to ensure subcriticality over the blanket lifetime. However, the very low subcriticality calculated for the two-dimensional base case $\left(k_{\text {eff }}=0.27\right.$ ) allowed room for improving the target/blanket performance characteristics. Therefore, a one-dimensional parameter optimization analysis using the transport code XSDRNPM was performed to determine the effect on the subcriticality of increasing the ${ }^{239} \mathrm{Pu}$ content. The same low-energy $(<20 \mathrm{MeV})$ neutron source was assumed since small changes in the ternary metal fuel composition would cause virtually no change in the high-energy cascade processes; i.e., a base case would yield a spatially distributed neutron source compatible with a range of fuel compositions. 


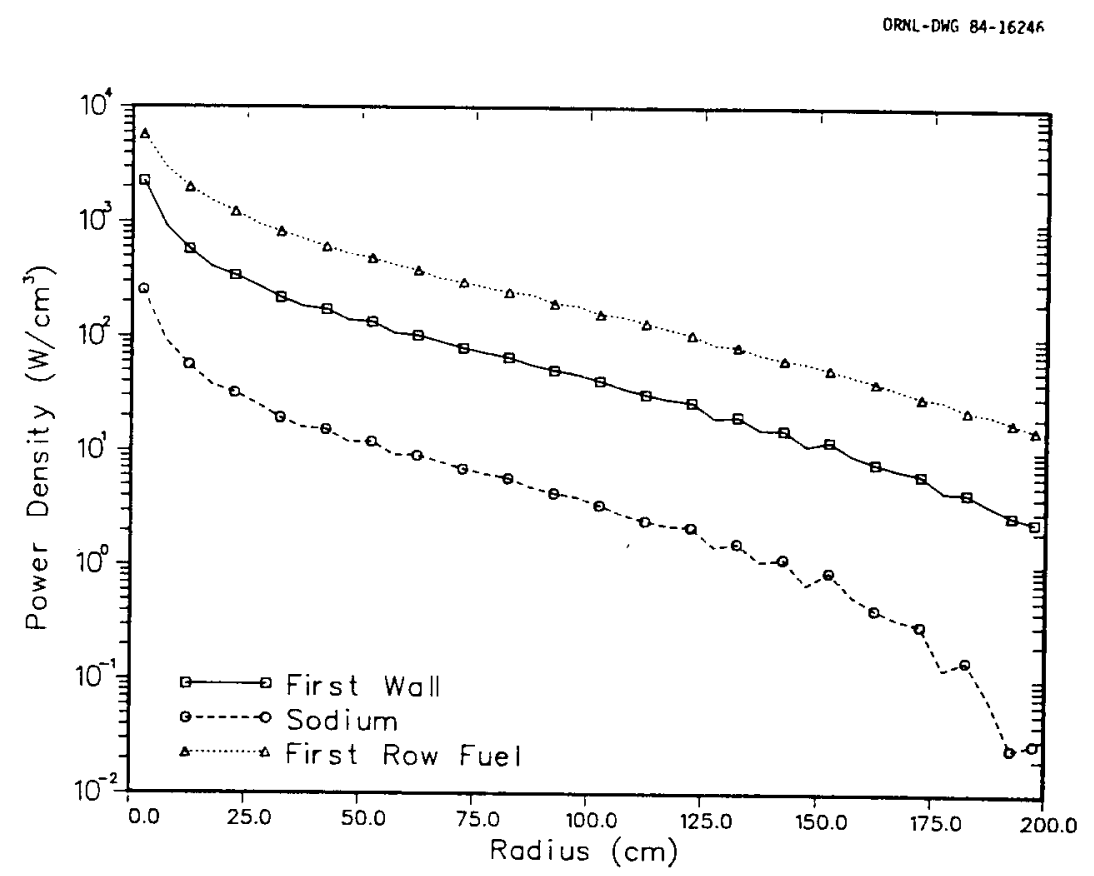

Fig. 12. Radial power density profiles of the first wall, sodium gap, and first row of fuel.

ORNL-DWG R4-16247

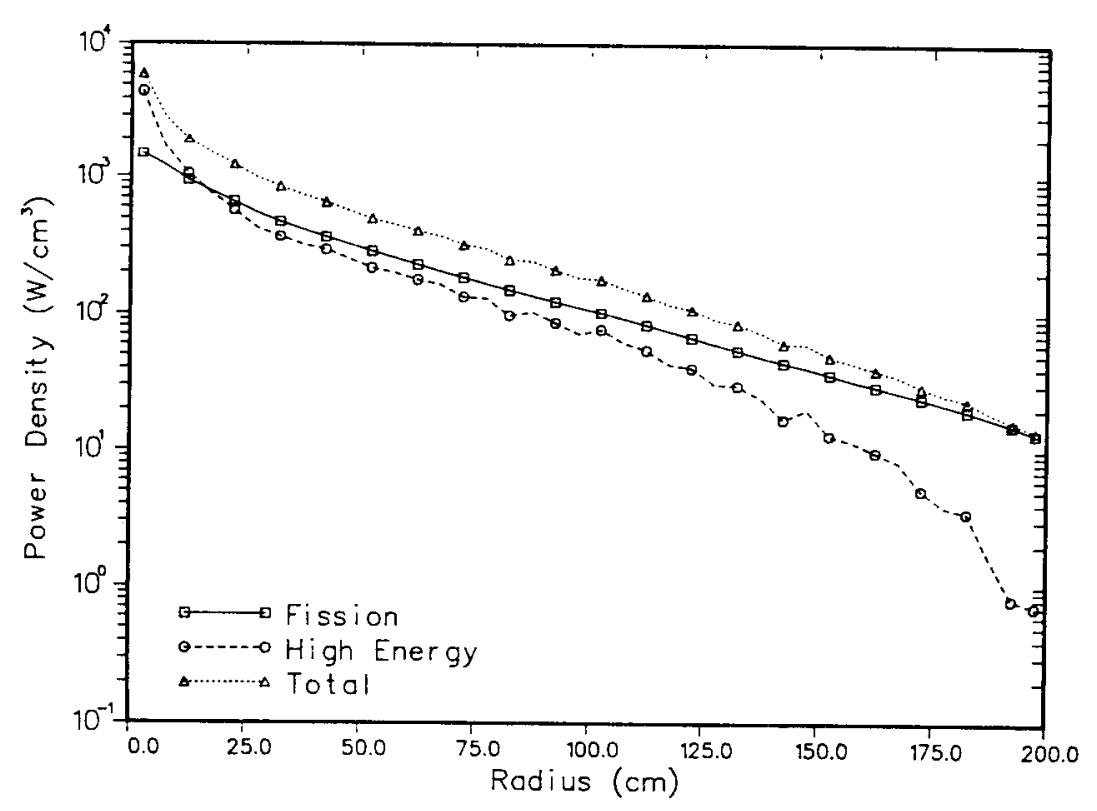

Fig. 13. Radial power density profiles of the target/blanket approximately $15 \mathrm{~cm}$ from the first wall. 
ORNL-DWG B4-1624B

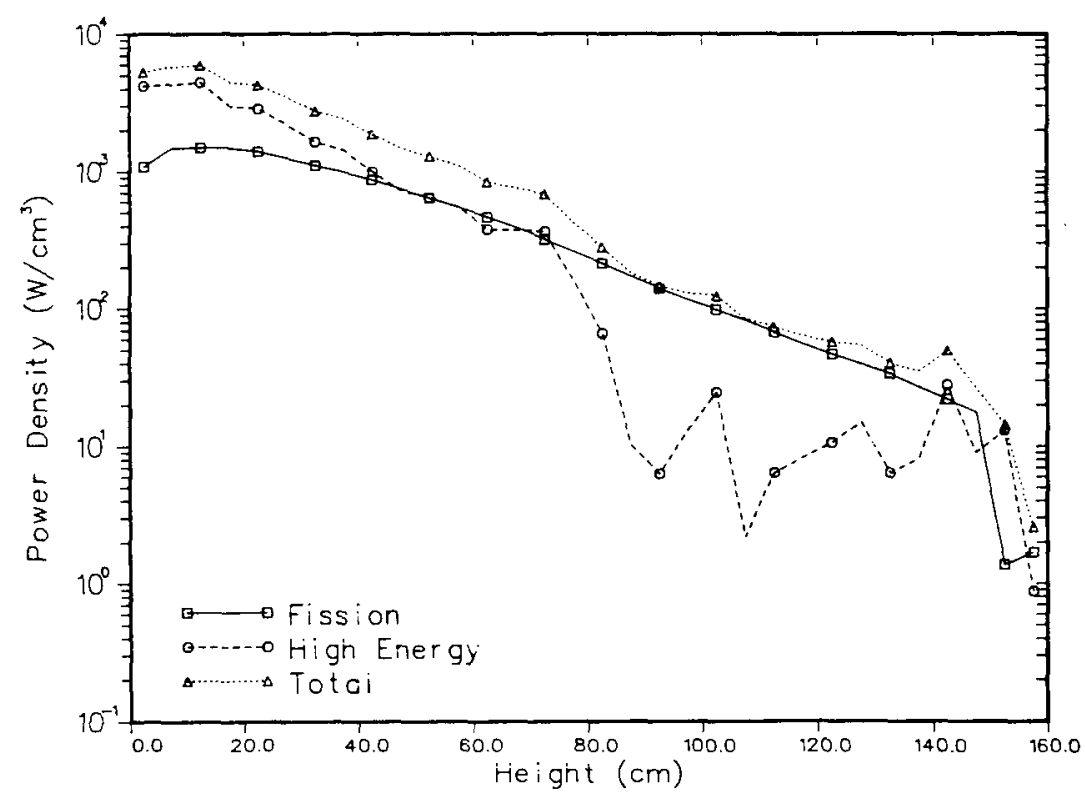

Fig. 14. Axial power density profiles of the target/blanket at $R=0$.

The model used in the one-dimensional transport analysis is shown in Fig. 15 and the fuel compositions are presented in Table 6. The results of the analysis, given in Table 10, indicate that the ${ }^{239} \mathrm{Pu}$ concentration can essentially be doubled to obtain the same beginning-of-cycle subcriticality obtained for the original design ( $k_{\text {eff }}=0.83$ in Table 10 versus $k_{\text {eff }}=0.84$ in Table 2) and, in fact, that the ${ }^{239} \mathrm{Pu}$ concentration can be increased to $7 \%$ with subcriticality still ensured. (Note: The Table $10 k_{\text {eff }}$ value of 0.20 for a $3 \%$ ${ }^{239} \mathrm{Pu}$ concentration is slightly lower than the value of 0.27 given in Table 8 owing to the loss of the backscattered neutrons, most of which are recovered in the two-dimensional calculations.)

As noted above, the principal function of the XSDRNPM one-dimensional transport analysis was to determine the blanket beginning-of-cycle subcriticality as a function of ${ }^{239} \mathrm{Pu}$ concentration, but another function was to create problem-dependent, regionweighted, $3 n$ libraries for the subsequent time-dependent burnup optimization calculations with ORIGEN-S. The validity of this procedure was tested by comparing the ORIGEN-S results obtained with the weighted library for the base target/blanket design (i.e., with $3 \%$ ${ }^{239} \mathrm{Pu}$ ) with the results that had been obtained in the two-dimensional DOT-4.3 analysis. As shown in Table 11, differences between the two cases were negligible and give positive reinforcement to the one-dimensional optimization study covering the fuel compositions given in Table 6.

The one-dimensional optimization study with ORIGEN-S began with calculations of the modified target/blanket performance of the various ternary metal compositions over a 90-day fuel cycle (270 FPDs per year). The results, summarized in Table 12, show a substantial increase in the net fissile fuel production rate - that is, the ${ }^{233} \mathrm{U}$ production rate 
ORNL-OWG 85-11457

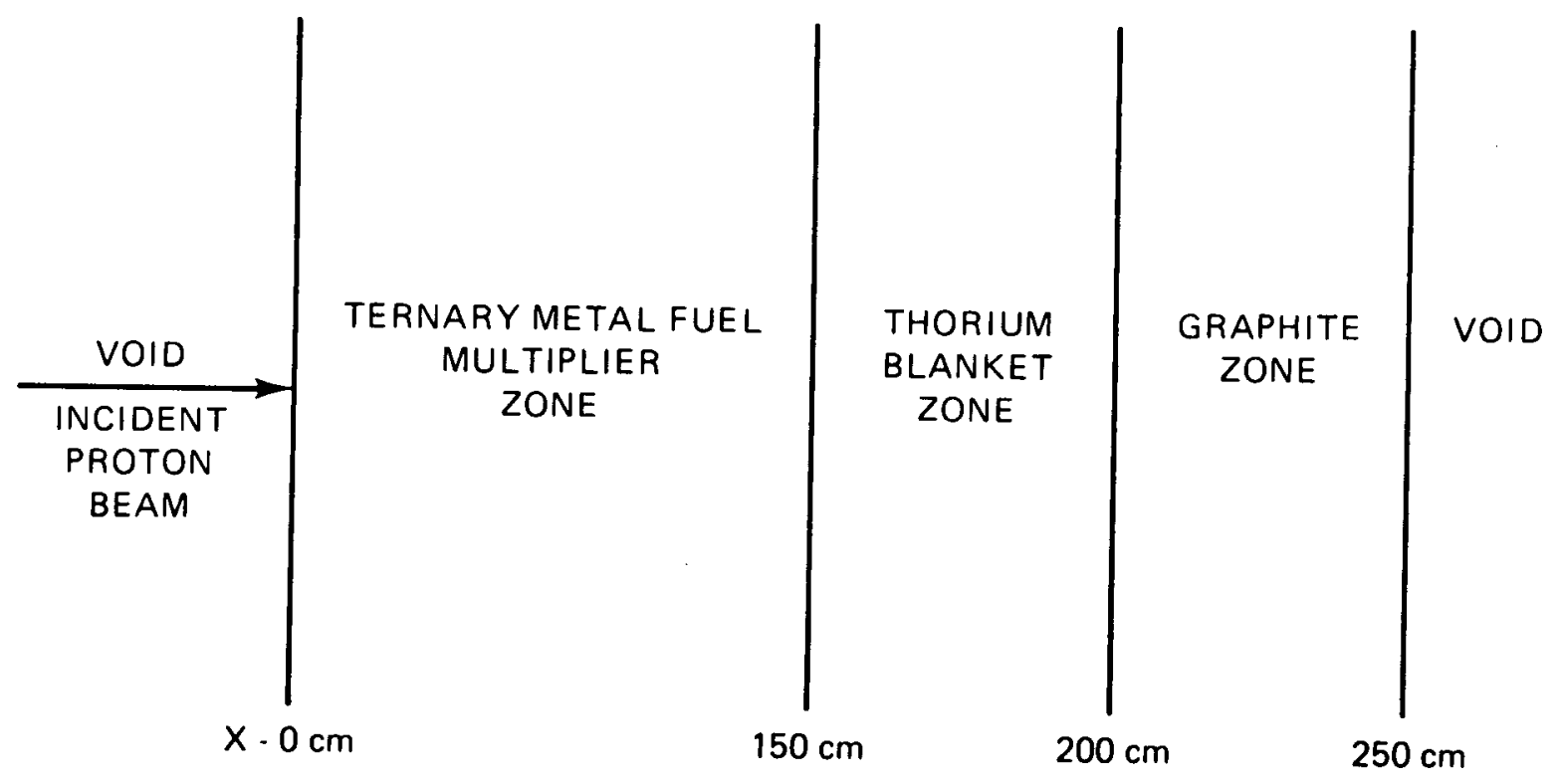

Fig. 15. One-dimensional transport model used in the parameter optimization study.

Table 10. System multiplication and $\boldsymbol{k}_{\text {eff }}$ results as a function of ${ }^{239} \mathrm{Pu}$ concentration in the ternary metal fuel

Percent

\begin{tabular}{ccc}
${ }^{239} \mathrm{Pu}$ in TMF & Multiplication & $k_{\text {eff }}$ \\
\hline $3^{a}$ & 1.25 & 0.20 \\
4 & 1.94 & 0.49 \\
5 & 3.15 & 0.68 \\
6 & 5.57 & 0.83 \\
7 & 15.68 & 0.94 \\
\hline
\end{tabular}

${ }^{a}$ Reference case. 
Table 11. Comparison of two-dimensional DOT-4.3 transport results and one-dimensional ORIGIN-S burnup results

at beginning of cycle (BOC)

\begin{tabular}{|c|c|c|}
\hline Parameter & DOT-4.3 & ORIGEN-S \\
\hline \multicolumn{3}{|c|}{ BOC neutron utilization by multiplier region } \\
\hline Percent absorbed in ${ }^{232} \mathrm{Th}$ & 64.4 & 64.9 \\
\hline Percent absorbed in ${ }^{239} \mathrm{Pu}$ & 18.3 & 18.4 \\
\hline Percent absorbed in ${ }^{238} \mathrm{U}$ & 15.4 & 15.5 \\
\hline $\begin{array}{l}\text { Percent absorbed in structure, } \\
\text { clad and coolant }\end{array}$ & 1.9 & 1.2 \\
\hline \multicolumn{3}{|l|}{ BOC neutron utilization by blanket region } \\
\hline Percent absorbed in ${ }^{232} \mathrm{Th}$ & 96.0 & 99.0 \\
\hline $\begin{array}{l}\text { Percent absorbed in structure, clad } \\
\text { and coolant }\end{array}$ & 4.0 & 1.0 \\
\hline Total neutron multiplication & 1.37 & 1.25 \\
\hline $\mathrm{BOC} k_{\mathrm{eff}}$ & 0.27 & 0.20 \\
\hline BOC thermal power, $M W(t)$ & 1535 & 1492 \\
\hline${ }^{233} \mathrm{U}$ production rate, $\mathrm{kg} / \mathrm{FPD}$ & 3.75 & 3.61 \\
\hline${ }^{239} \mathrm{Pu}$ net destruction rate, $\mathrm{kg} / \mathrm{FPD}$ & 0.32 & 0.31 \\
\hline
\end{tabular}

Table 12. Modified target/blanket performance as a function of ${ }^{239} \mathrm{Pu}$ concentration in the ternary metal fuel

\begin{tabular}{cccccc}
\hline $\begin{array}{c}{ }^{239} \mathrm{Pu} \\
\begin{array}{c}\text { concentration } \\
(\%)\end{array}\end{array}$ & $\begin{array}{c}\text { Power } \\
{[\mathrm{MW}(\mathrm{t})]}\end{array}$ & $\begin{array}{c}{ }^{233} \mathrm{U} \\
\text { production } \\
\text { rate } \\
(\mathrm{kg} / \mathrm{FPD})\end{array}$ & $\begin{array}{c}{ }^{239} \mathrm{Pu} \text { net } \\
\text { destruction } \\
\text { rate } \\
(\mathrm{kg} / \mathrm{FPD})\end{array}$ & $\begin{array}{c}{ }^{228} \mathrm{Th} \\
\text { production } \\
\text { rate } \\
(\mathrm{kg} / \mathrm{FPD})\end{array}$ & $\begin{array}{c}{ }^{232} \mathrm{U} \\
\text { production } \\
\text { rate } \\
(\mathrm{kg} / \mathrm{FPD})\end{array}$ \\
\hline 3 & 1492 & 3.61 & 0.31 & $5.19-06$ & $7.04-03$ \\
4 & 2078 & 4.49 & 0.68 & $7.04-06$ & $8.89-03$ \\
5 & 3092 & 6.01 & 2.04 & $1.00-05$ & $1.30-02$ \\
6 & 5292 & 9.29 & 3.41 & $1.78-05$ & $2.22-02$ \\
\hline
\end{tabular}


less the ${ }^{239} \mathrm{Pu}$ net destruction rate - as the ${ }^{239} \mathrm{Pu}$ concentration increased. Also, the thermal power generated in the blanket increased by a factor of approximately 3.5 when the ${ }^{239} \mathrm{Pu}$ concentration was doubled. Finally, the efficiency of the design was confirmed since the ${ }^{233} \mathrm{U}$ production rate and thermal power for a $5 \%{ }^{239} \mathrm{Pu}$ concentration $[6.0 \mathrm{~kg} / \mathrm{FPD}$ and $3092 \mathrm{MW}(\mathrm{t})$ ] were approximately equal to that of the original design [5.9 $\mathrm{kg} / \mathrm{FPD}$ and $3300 \mathrm{MW}(\mathrm{t})$; see Table 2] for a factor of two decrease in the system multiplication [i.e., 3.15 (in Table 10) versus 6.30 (in Table 2)].

The results of the $7 \%{ }^{239} \mathrm{Pu}$ concentration are not included in Table 12 because the thermal power production was calculated to be so large $[13,400 \mathrm{MW}(\mathrm{t})]$ that it would not be possible to cool the system. Therefore, $6 \%{ }^{239} \mathrm{Pu}$ was determined to be the maximum allowable concentration in the ternary metal fuel.

Next, the neutronic optimization study included an investigation of the target/blanket performance as a function of the fuel cycle length. Even though the radiation-damage analysis had indicated that the first wall would be limited to 90 days, it was recognized that advances in materials research could extend this value and the target/blanket performance for extended cycles would need to be known. The analysis involved calculating the key neutronic parameters over cycle lengths of 45 days, 90 days, 180 days, and 270 days for ${ }^{239} \mathrm{Pu}$ concentrations of $3,4,5$, and $6 \%$.

Figure 16 shows that the target/blanket thermal power increased slightly as a function of irradiation cycle length. This was primarily due to the increased fission rate from ${ }^{233} \mathrm{U}$ fissile material bred into the fuel. It should be noted that the increase in power was greater for the higher concentrations of ${ }^{239} \mathrm{Pu}$ in the fuel. This trend was due to the slight decrease in net ${ }^{233} U$ production as a function of cycle length (see Fig. 17). As the cycle length was extended, some of the ${ }^{233} U$ fissile fuel burned up and therefore the net amount of fuel produced decreased.

The byproducts ${ }^{232} \mathrm{U}$ and ${ }^{228} \mathrm{Th}$, analyzed primarily because they emit high-energy gamma rays, both showed increases in production as the fuel cycle length increased (see Figs. 18 and 19). The results indicate that the ${ }^{232} \mathrm{U}$ production approached equilibrium conditions at a much faster rate than the ${ }^{228} \mathrm{Th}$ production. Furthermore, a much larger quantity of ${ }^{232} \mathrm{U}$ was produced in the target/blanket.

The final calculations performed in the neutronic optimization study compared two reprocessing modes for extracting bred fissile material and adding makeup fuel as a function of cycle length. The pebble-type fuel used in the modified target/blanket design affords the option of either continuous on-line fuel reprocessing or batch fuel reprocessing. In these calculations similar trends were noted for various ${ }^{239} \mathrm{Pu}$ concentrations; therefore, only the results of the $5 \%{ }^{239} \mathrm{Pu}$ concentration case are presented. Figures 20,21 , and 22 show the target/blanket thermal power, the ${ }^{233} \mathrm{U}$ production rate, and the ${ }^{228} \mathrm{Th}$ and ${ }^{232} \mathrm{U}$ production rates, respectively, for the $5 \%{ }^{239} \mathrm{Pu}$ case.

The points on the on-line reprocessing curves in Figs. 20-22 represent the equilibrium concentrations (or in Fig. 20, the power) following initial irradiation periods set equal to those used in the batch reprocessing analysis. Therefore, for the on-line reprocessing case, the value at 90 days represents the equilibrium value attained from continuous reprocessing after 90 days of irradiation without any reprocessing. 
ORNL-DHG 84-16250

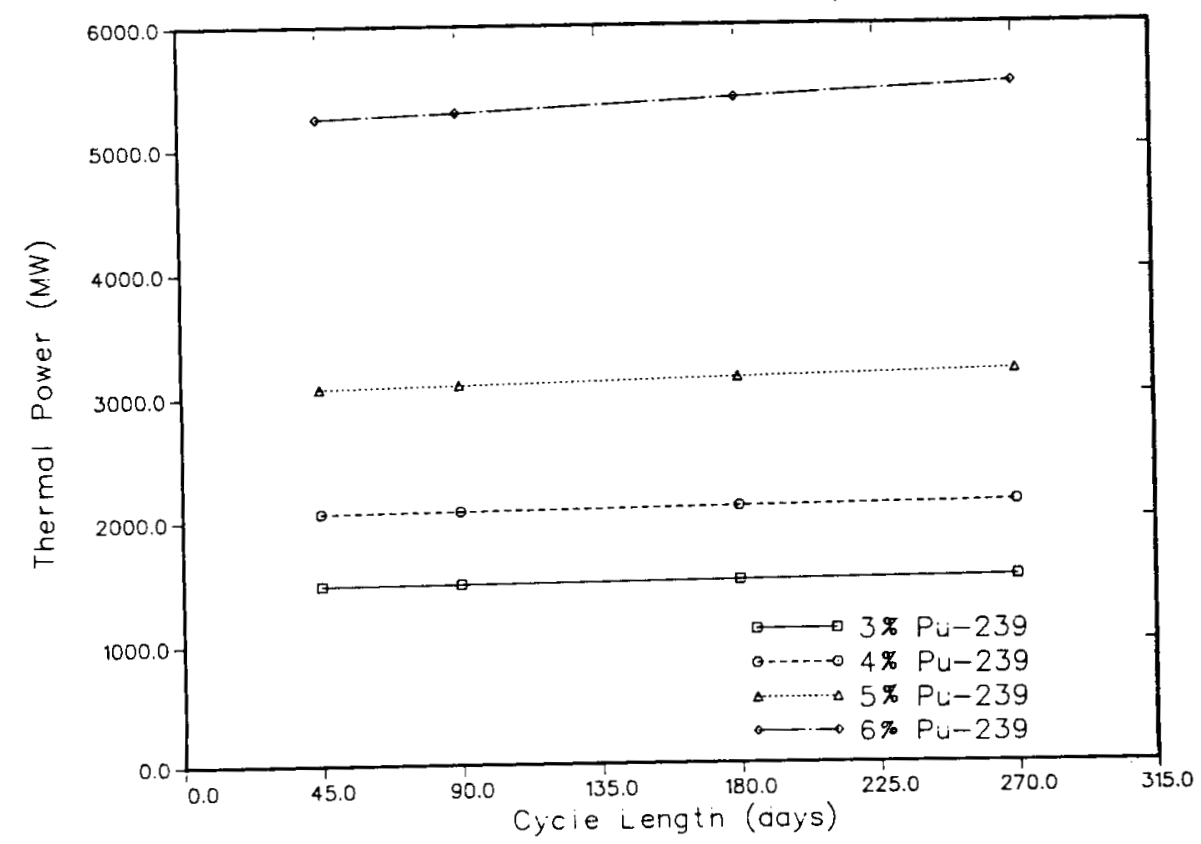

Fig. 16. Modified target/blanket thermal power as a function of cycle length and ${ }^{239} \mathrm{Pu}$ concentration.

OPNL-DWG 84-16251

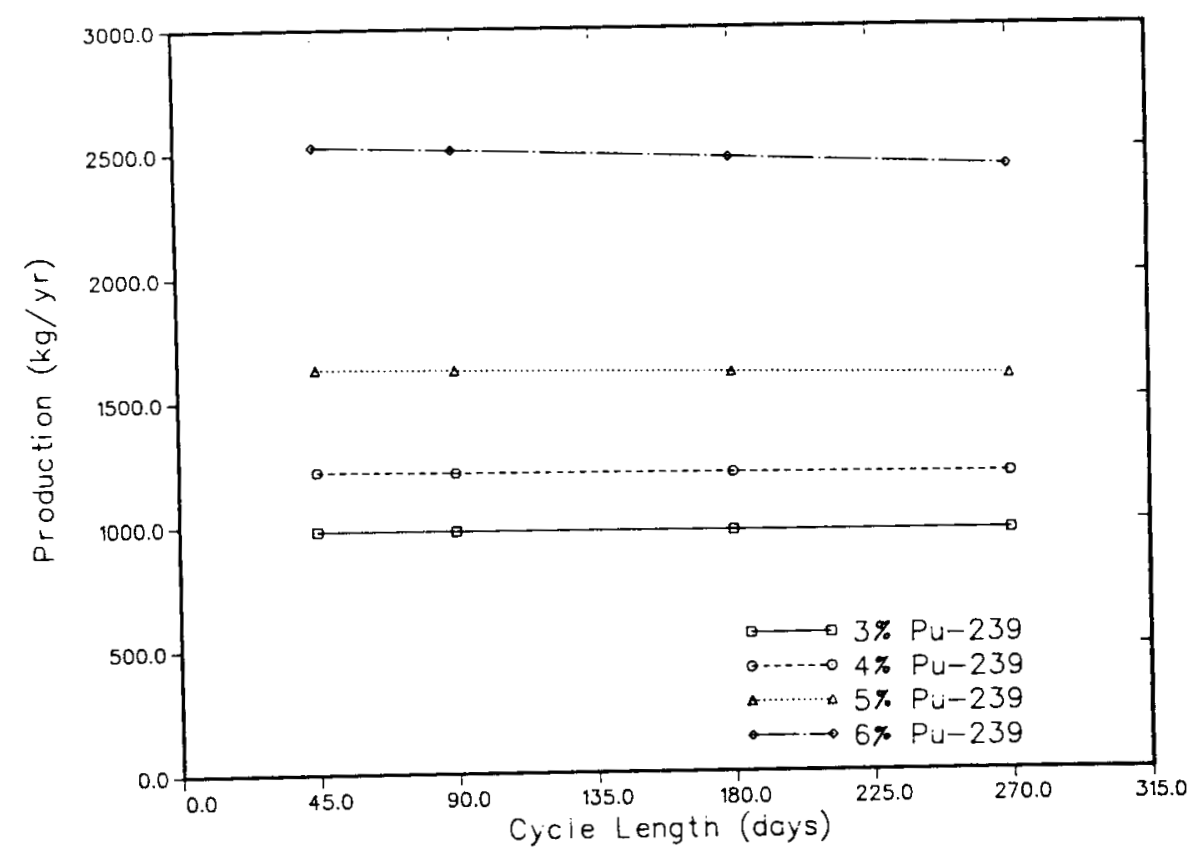

Fig. 17. Modified target/blanket ${ }^{233} \mathrm{U}$ production as a function of cycle length and ${ }^{239} \mathrm{Pu}$ concentration. 
ORNL-DWS BA-16252

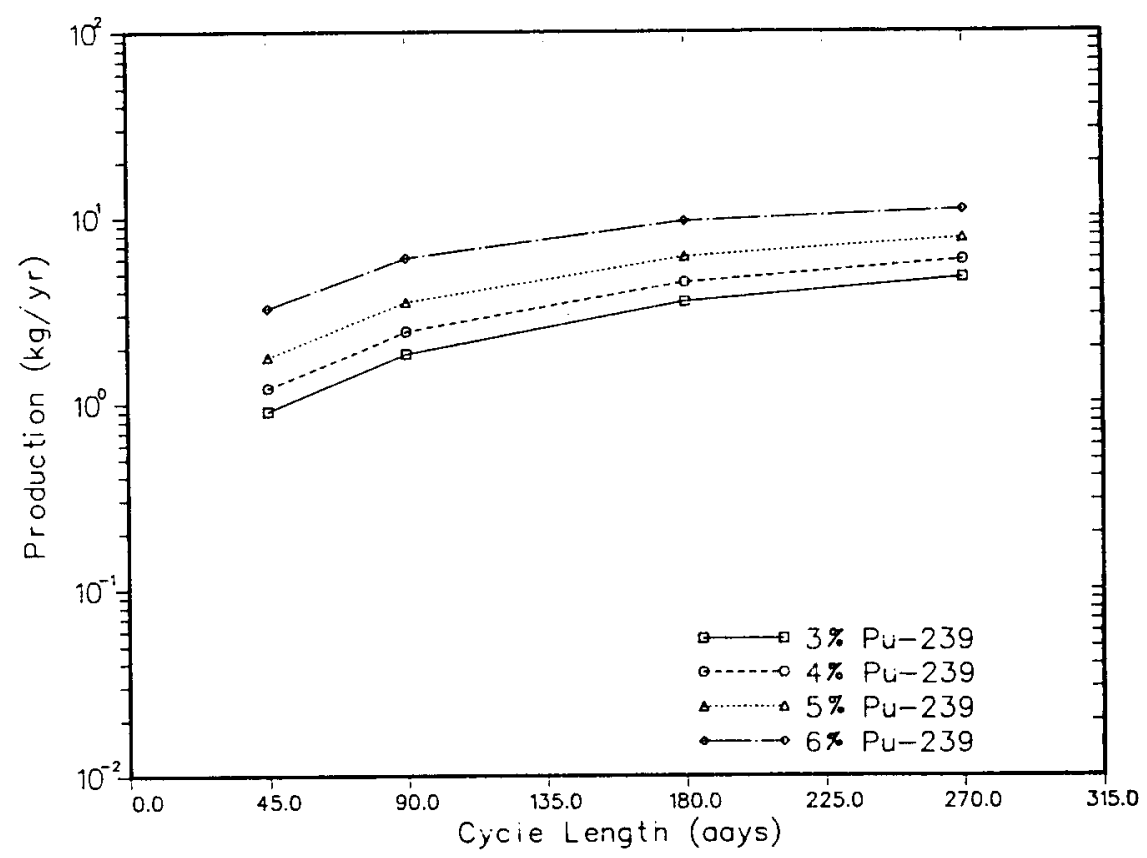

Fig. 18. Modified target/blanket ${ }^{232} \mathrm{U}$ production as a function of cycle length and ${ }^{239} \mathrm{Pu}$ concentration.

ORNL-DHG BA-16253

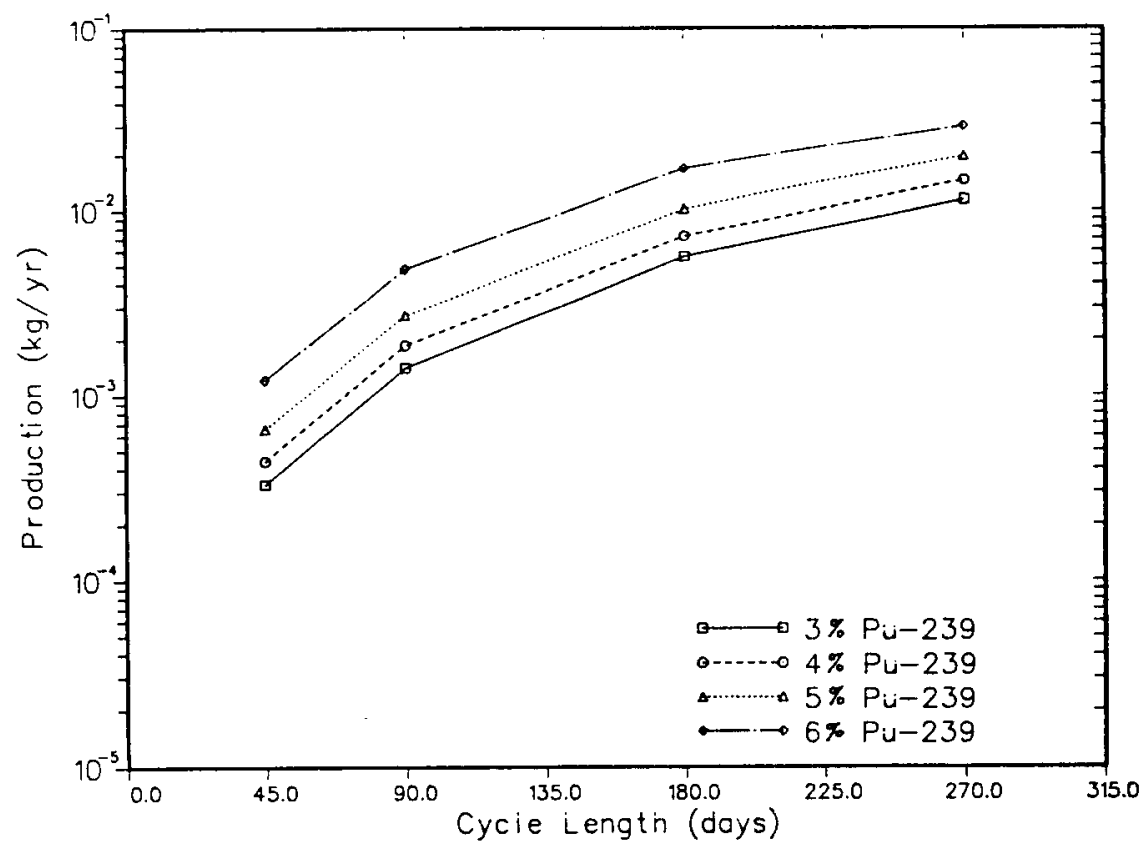

Fig. 19. Modified target/blanket ${ }^{228} \mathrm{Th}$ production as a function of cycle length and ${ }^{239} \mathrm{Pu}$ concentration. 
ORNL-DHG 84-16254

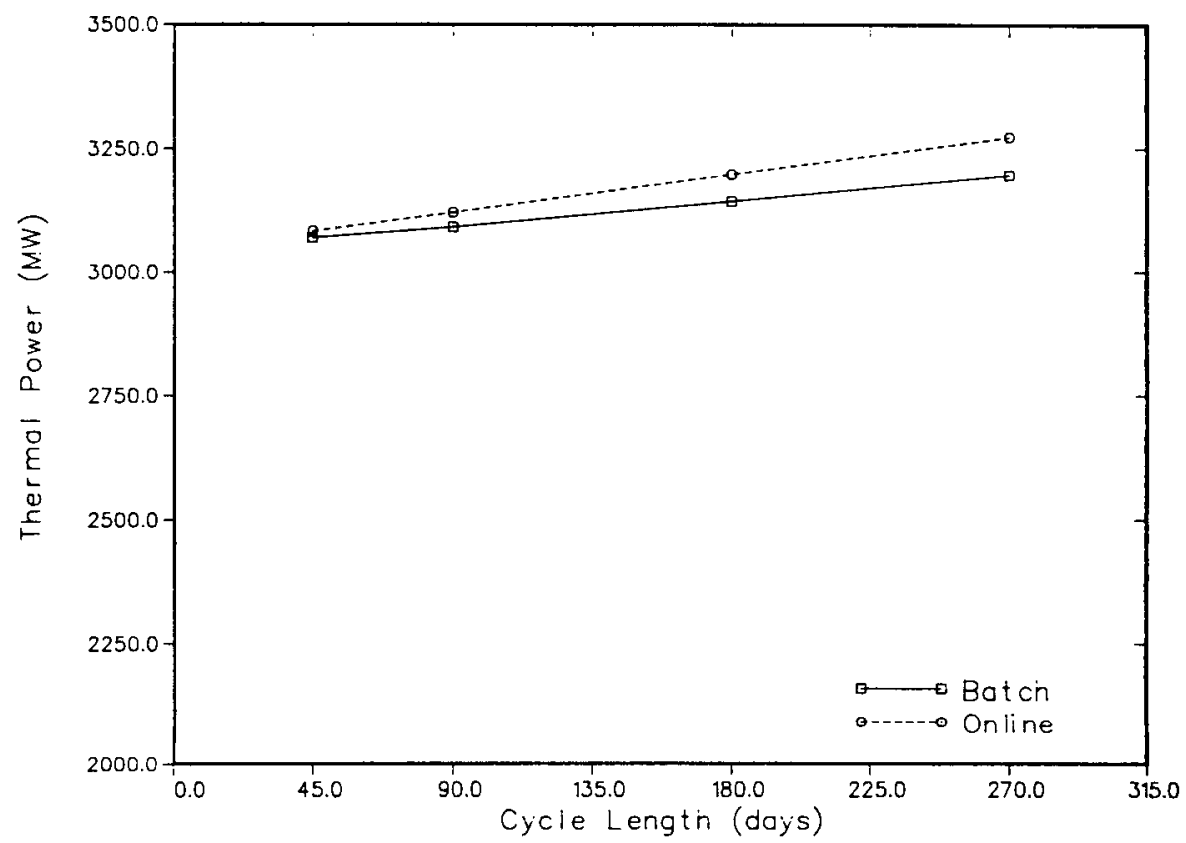

Fig. 20. Modified target/blanket thermal power production for the $5 \%{ }^{239} \mathrm{Pu}$ ternary metal fuel as a function of reprocessing mode.

ORNL-DWG 84-16255

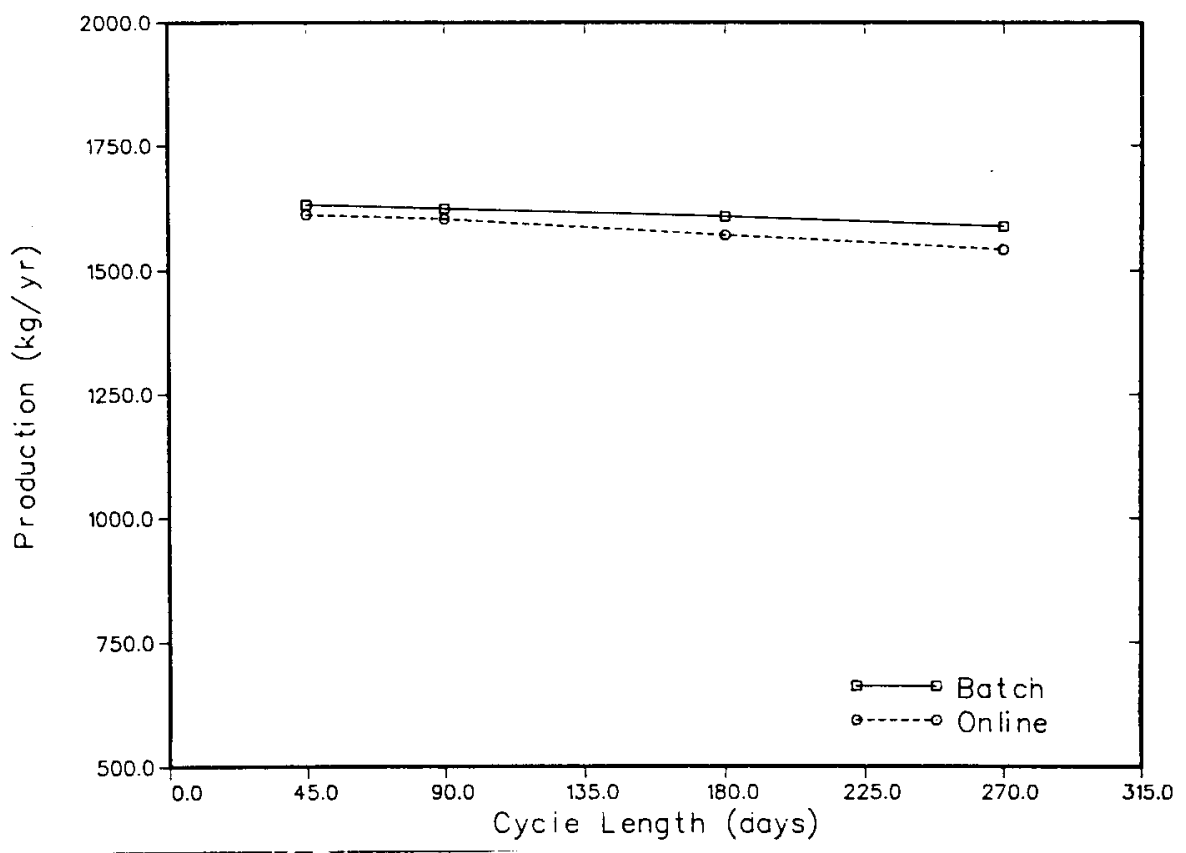

Fig. 21. Modified target/blanket ${ }^{233} \mathrm{U}$ production for the $5 \%{ }^{239} \mathrm{Pu}$ ternary metal fuel as a function of reprocessing mode. 


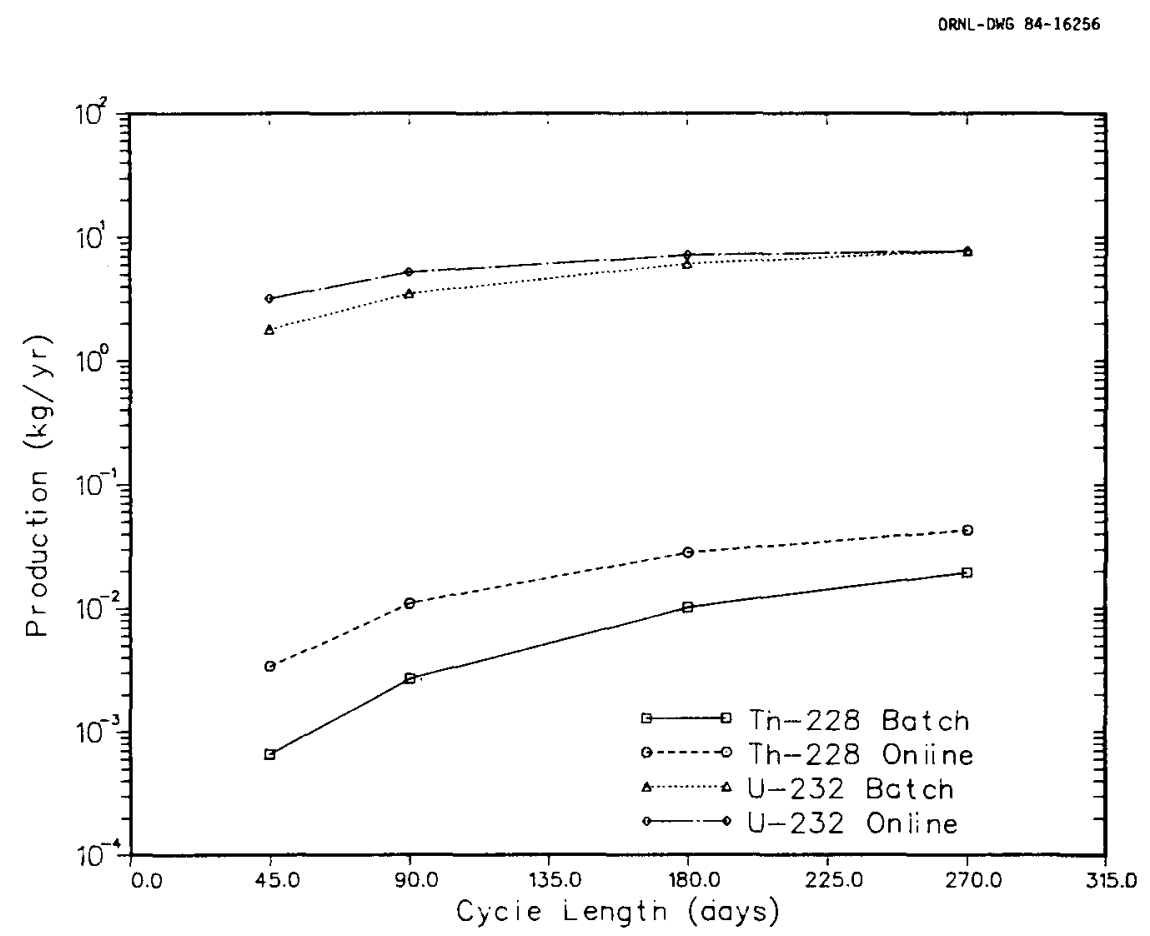

Fig. 22. Modified target/blanket ${ }^{232} \mathrm{U}$ and ${ }^{228} \mathrm{Th}$ production for the $5 \%{ }^{239} \mathrm{Pu}$ ternary metal fuel as a function of reprocessing mode.

Figures 20 and 21 show that continuous fuel reprocessing results in a higher target/blanket thermal power but a lower net ${ }^{233} \mathrm{U}$ production. The plots in Figs. 20 and 21 diverge as the cycle length increases, which is to be expected since the ${ }^{233} U$ concentration is higher in the on-line reprocessing mode and therefore more ${ }^{233} \mathrm{U}$ will undergo fission, which will raise the thermal power output and lower the net ${ }^{233} \mathrm{U}$ production.

In the case of the production of ${ }^{232} \mathrm{U}$ and ${ }^{228} \mathrm{Th}$ (Fig. 22), the batch reprocessing mode contains lower concentrations of both isotopes; however, the concentrations for the two modes tend to converge as the cycle length increases. The total convergence of the curves for ${ }^{232} U$ production at 270 days indicates that equilibrium concentrations of this isotope have been reached. On the other hand, the results for the ${ }^{228} \mathrm{Th}$ appear to be a long way from convergence, a large difference remaining in the calculat ${ }^{-1}$ concentrations in the output streams for the two reprocessing cases.

For the heat-transfer and thermal-hydraulic parameter optimization study performed with HEATING6, an empirical correlation for liquid sodium flowing around a heated sphere was used, together with the energy deposition results indicated from the HETC high-energy transport calculation and the DOT-4.3 low-energy transport calculation. The fuel centerline temperature and first-wall temperature were investigated with respect to sodium velocity, the fuel pebble diameter, and the ${ }^{239} \mathrm{Pu}$ concentration. The forced convective heat-transfer coefficients used in the analysis are shown graphically in Fig. 23 as a function of fuel pebble diameter and sodium velocity. 


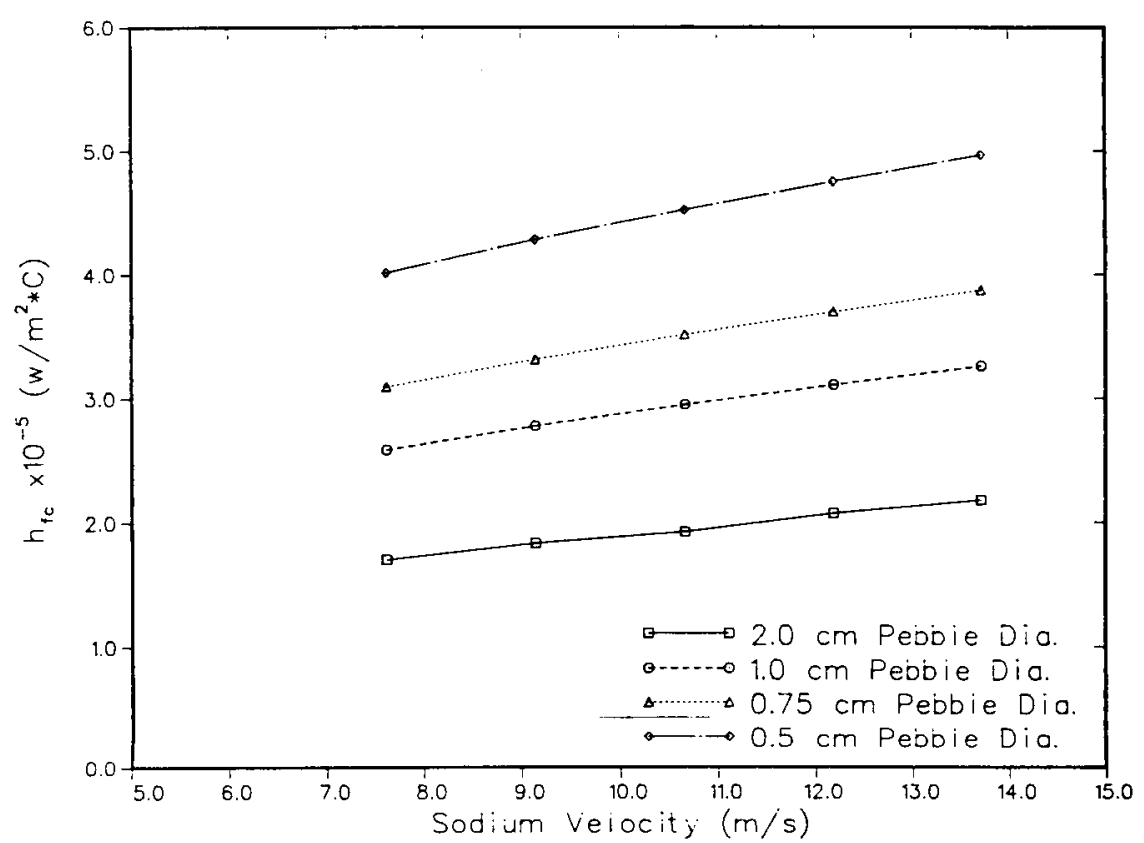

Fig. 23. Forced convective heat-transfer coefficients as a function of sodium velocity and fuel pebble diameter.

The fuel centerline temperatures for a $3 \%{ }^{239} \mathrm{Pu}$ concentration and a $6 \%{ }^{239} \mathrm{Pu}$ concentration in the ternary metal fuel are shown in Figs. 24 and 25, respectively. (The 4\% ${ }^{239} \mathrm{Pu}$ and $5 \%{ }^{239} \mathrm{Pu}$ concentration results are encompassed by these results and therefore are not presented.) The analyses were performed for the target/blanket hot spot, which was approximately $15 \mathrm{~cm}$ from the first wall along the central axis. The results indicate virtually no sensitivity to the sodium velocity over the range of 7 to $14 \mathrm{~m} / \mathrm{s}$ (20 to $40 \mathrm{ft} / \mathrm{s})$. They also indicate that the fuel pebble diameter must be less than $1.0 \mathrm{~cm}$ to ensure adequate cooling in the target/blanket hot spot. The $6 \%{ }^{239} \mathrm{Pu}$ concentration fuel pebble (Fig. 25) with a maximum power density of approximately $12 \mathrm{~kW} / \mathrm{cm}^{3}$ and a fuel sphere diameter of $0.50 \mathrm{~cm}$ has a centerline fuel temperature of approximately $850^{\circ} \mathrm{C}$, and increasing the pebble diameter to just $0.75 \mathrm{~cm}$ raises the temperature to approximately $1250^{\circ} \mathrm{C}$. As mentioned earlier, the principal reason for these high temperatures is the peaked power density in the target/blanket due to the incident proton beam profile.

The first-wall hot-spot temperatures are shown in Fig. 26 for a $0.5-\mathrm{cm}$-thick wall and in Fig. 27 for a $0.4-\mathrm{cm}$-thick wall. These calculations were performed for a $3 \%{ }^{239} \mathrm{Pu}$ concentration in the ternary metal fuel. Again, virtually no sensitivity to sodium flow rate was indicated. Furthermore, the maximum thickness for coolability was found to be 0.4 $\mathrm{cm}$ (Fig. 27), which indicates that the first wall will have to function strictly as a window between the proton beam and the target/blanket with the present incident beam profile. Even with the $0.4-\mathrm{cm}$-thick first wall and a 0.5 -cm-diameter fuel pebble, the first-wall hot-spot temperature was approximately $1080^{\circ} \mathrm{C}$. However, for these calculations it was 
ORNL-DHG R4-16258

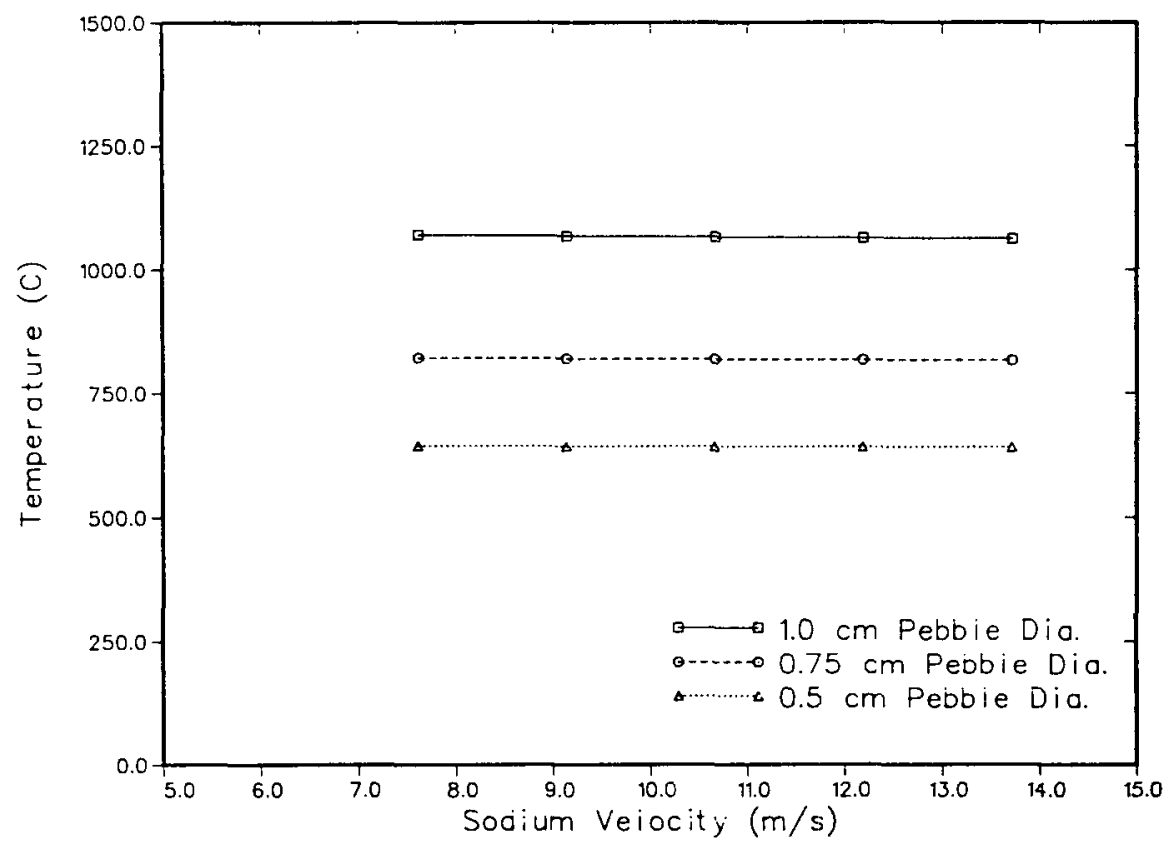

Fig. 24. Ternary metal fuel centerline temperature for the $3 \%{ }^{239} \mathrm{Pu}$ concentration as a function of sodium velocity and pebble diameter.

ORNL-DWG RA-16259

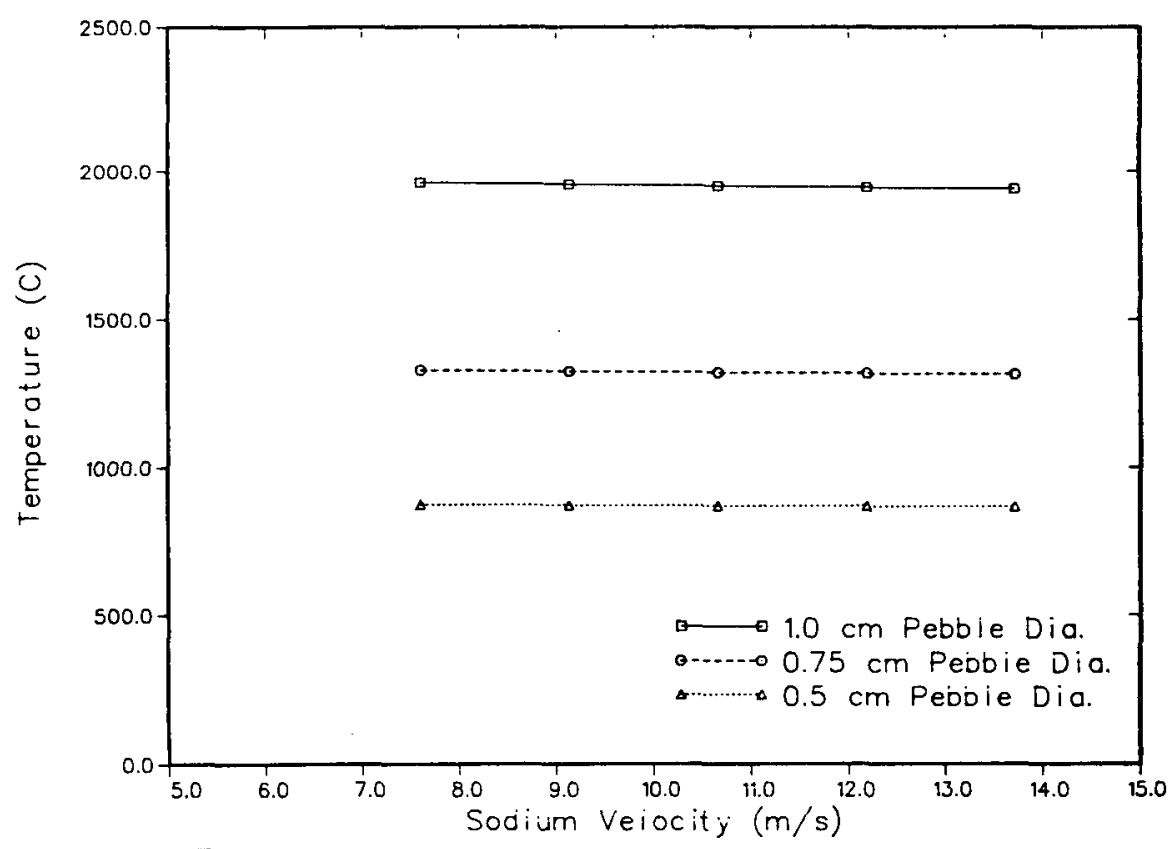

Fig. 25. Ternary metal fuel centerline temperature for the $6 \%{ }^{239} \mathrm{Pu}$ concentration as a function of sodium velocity and pebble diameter. 
ORNL-DHG B4-16260

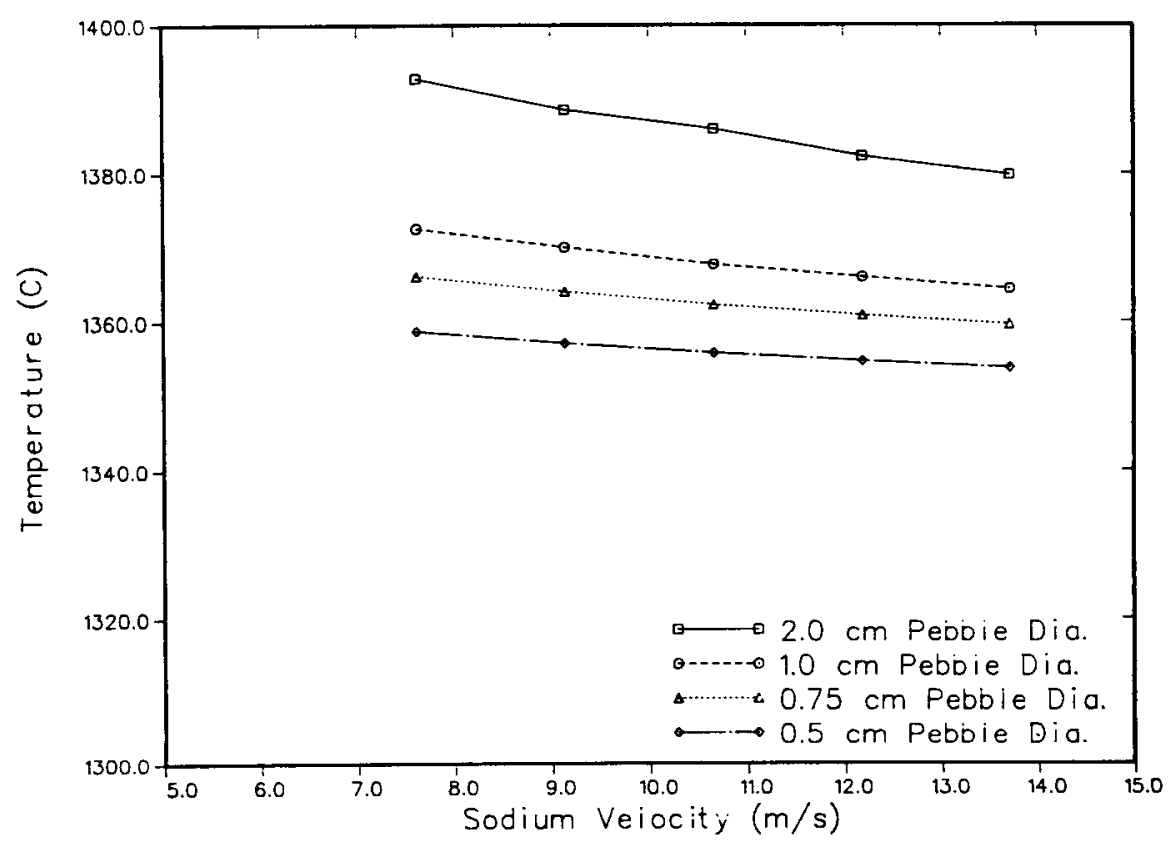

Fig. 26. Hot-spot temperatures for a $0.5-\mathrm{cm}$-thick first wall as a function of sodium velocity and pebble diameter.

OANL-DWG $84-16261$

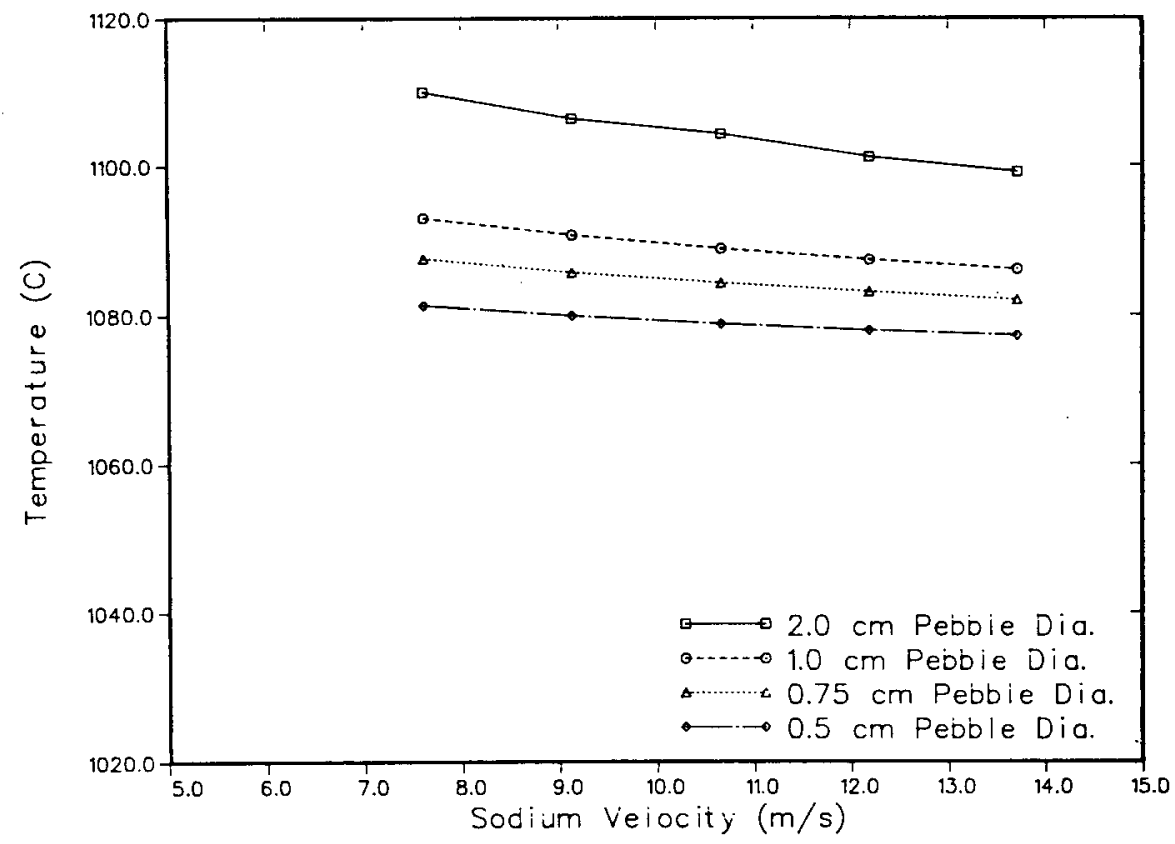

Fig. 27. Hot-spot temperatures for a $\mathbf{0 . 4 - c m - t h i c k ~ f i r s t ~ w a l l ~ a s ~ a ~ f u n c t i o n ~ o f ~ s o d i u m ~}$ velocity and pebble diameter. 
assumed that the sodium coolant entered the sides of the blanket and flowed to the middle, having an inlet temperature of $327^{\circ} \mathrm{C}$ and an exit temperature of approximately $562^{\circ} \mathrm{C}$. As seen in Fig. 28, reversing the sodium flow so that the sodium entered the center of the target/blanket (at $327^{\circ} \mathrm{C}$ ) and exited the sides (at $562^{\circ} \mathrm{C}$ ) decreased the $0.4-\mathrm{cm}$-thick first-wall hot-spot temperature with a $0.5-\mathrm{cm}$ fuel pebble down to approximately $875^{\circ} \mathrm{C}$. This value is approaching the region of acceptable values for steel (i.e., $650-750^{\circ} \mathrm{C}$ ).

On the basis of the optimization studies, a preliminary semioptimized TMF-ENFP design was arrived at. The design parameters for the semioptimized TMF-ENFP are given in Table 13, and the system's key neutronic and thermal-hydraulic performance parameters are given in Table 14.

OPNL - DHF 84-16262

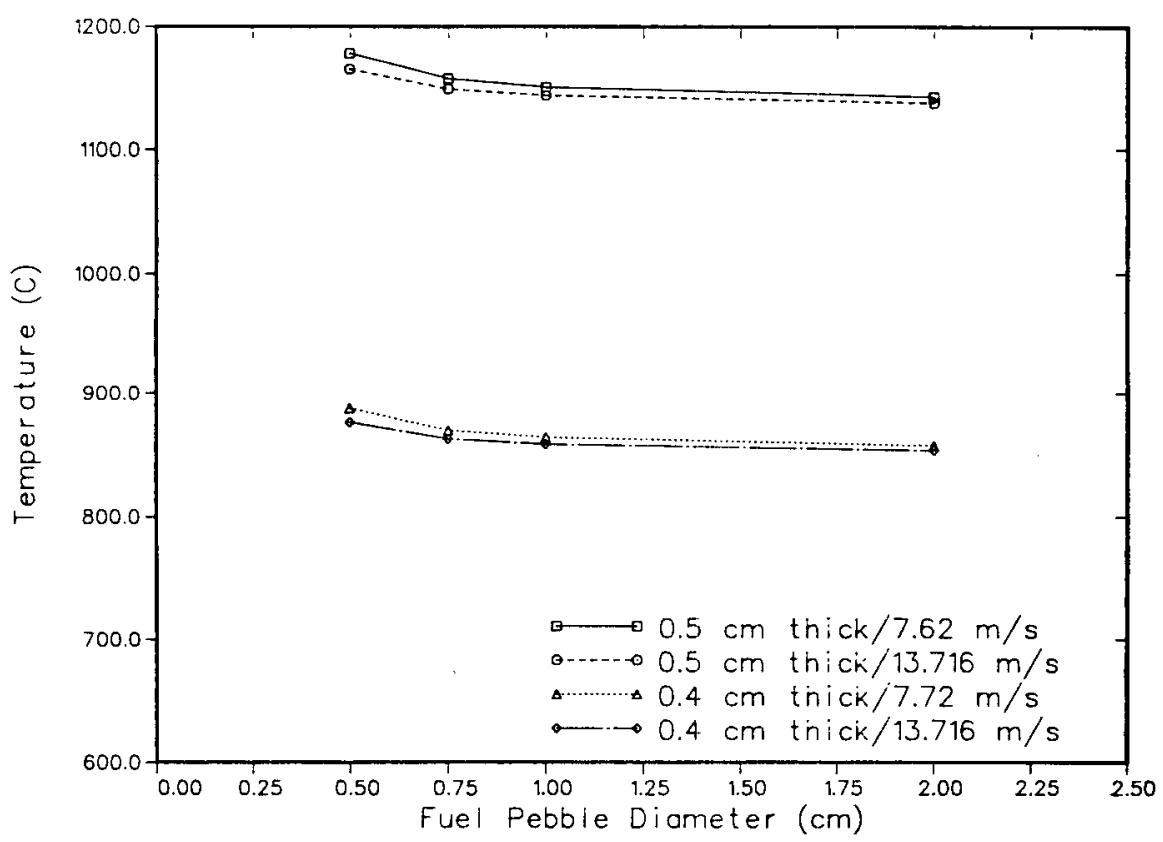

Fig. 28. Hot-spot temperatures for the first wall with reversed sodium flow as a function of sodium velocity and pebble diameter. 
Table 13. Design parameters of the semioptimized TMF-ENFP target/blanket design

First wall:

Composition

Thickness, cm

Target/multiplier region:

Composition

Sphere outside diameter, $\mathrm{cm}$

Clad material

Clad thickness, $\mathrm{cm}$

Structure material

$V_{\text {Fuel }} / V_{\text {Coolant }} / V_{\text {Structure }}$
V - $20 \%$ Ti steel

0.4

Ternary metal $\left(78 \%{ }^{232} \mathrm{Th}, 16 \%{ }^{238} \mathrm{U}, 6 \%{ }^{239} \mathrm{Pu}\right)$

0.5

Nickel

$2.0 \times 10^{-4}$ (nominal)

$\mathrm{V}-20 \%$ Ti steel

$0.5236 / 0.4264 / 0.05$

${ }^{232} \mathrm{Th}$ metal

0.5

Nickel

$2.0 \times 10^{-4}$ (nominal)

$\mathrm{V}-20 \%$ Ti steel

$0.5236 / 0.4264 / 0.05$

Graphite

Reflector region:

Composition

Shield region:

Composition 
Table 14. Summary of modified (semioptimized) TMF-ENFP neutronic and thermal-hydraulic performance parameters

\begin{tabular}{ll}
\hline Nuclear: & \\
$k_{\text {eff }}$ - BOC & 0.83 \\
$k_{\text {eff }}$ EOC & 0.82 \\
Multiplication - BOC & 5.75 \\
Multiplication - EOC & 5.56 \\
${ }^{233} \mathrm{U}$ production rate & $9.29 \mathrm{~kg} / \mathrm{FPD}$ \\
${ }^{239} \mathrm{Pu}$ net destruction rate & $3.41 \mathrm{~kg} / \mathrm{FPD}$ \\
Fissile loading & $15100 \mathrm{~kg}$ \\
Residence time & $90 \mathrm{FPD}$ \\
& \\
Thermal hydraulic: & \\
Thermal power - BOC & $5240 \mathrm{MW}(\mathrm{t})$ \\
Thermal Power - EOC & $5291 \mathrm{MW}(\mathrm{t})$ \\
Na inlet temperature & $327^{\circ} \mathrm{C}$ \\
Maximum sodium outlet temperature & $562^{\circ} \mathrm{C}$ \\
Na velocity & $9.14 \mathrm{~m} / \mathrm{sec}$ \\
Peak centerline temperature & $850^{\circ} \mathrm{C}$ \\
Peak cladding temperature & $800^{\circ} \mathrm{C}$ \\
Peak first wall temperature & $875^{\circ} \mathrm{C}$ \\
Maximum first wall power density & $2500 \mathrm{~W} / \mathrm{cm}^{3}$ \\
Maximum radial power density & $12000 \mathrm{~W} / \mathrm{cm}^{3}$ \\
Maximum smear power density & $1100 \mathrm{~W} / \mathrm{cm}^{3}$ \\
\hline
\end{tabular}




\section{CONCLUSIONS AND RECOMMENDATIONS}

\subsection{CONCLUSIONS}

Several specific conclusions can be drawn from the design and performance parameters of the modified (semioptimized) TMF-ENFP. First, the system $k_{\text {eff }}$ and multiplication remain virtually constant over the irradiation cycle length, thereby yielding a stable system for heat removal design. The system $k_{\text {eff }}$ does decrease somewhat as a function of cycle length, whereas it increased in the original TMF-ENFP design, ${ }^{18}$ and this represents an added safety feature to the target/blanket.

The ${ }^{233} \mathrm{U}$ fissile production rate is approximately $60 \%$ higher in the modified design than in the original design, with the net fissile destruction rate for ${ }^{239} \mathrm{Pu}$ being only $17 \%$ higher. The initial fissile loading of $15,100 \mathrm{~kg}{ }^{239} \mathrm{Pu}$ is prohibitively large; however, the burning of ${ }^{239} \mathrm{Pu}$ at a rate of $3.41 \mathrm{~kg} / \mathrm{FPD}(\sim 920 \mathrm{~kg} / \mathrm{year})$ means that the annual discharge of approximately six Light Water Reactors (LWRs) would fuel the TMFENFP. In turn, the $9.29 \mathrm{~kg} / \mathrm{FPD}$ of bred ${ }^{233} \mathrm{U}(\sim 2508 \mathrm{~kg} /$ year $)$ would support the annual makeup requirements of approximately nine LWRs. Therefore, once initial inventory is obtained, the TMF-ENFP could realistically support nine LWRs in a closed cycle.

The thermal power generated by the target/blanket in the modified design was also approximately $60 \%$ higher than that of the original design at beginning-of-cycle. However, the thermal power remained constant over cycle length, whereas in the original design it underwent a power swing of $1200 \mathrm{MW}(\mathrm{t})$. A flat power profile over cycle length enables a better secondary-side heat-removal design. Furthermore, the amount of thermal power generated is more than enough to make the TMF-ENFP self sufficient in its own energy balance, with the possibility of selling excess power to the commercial grid.

The parameters for the sodium coolant remained virtually unchanged in the modified design; however, the peak temperatures on the fuel centerline and in the cladding increased substantially, primarily because the ternary metal fuel resides directly in the path of the incident proton beam and thus absorbs more energy than it did in the original design. This is illustrated by comparing the maximum radial power densities and the maximum smear power densities for the two designs. The maximum smear power densities are equal, but the maximum radial power densities differ by a factor of almost four. In the modified target/blanket design, $37.5 \%$ of the maximum radial power density is due to high-energy reactions and $62.5 \%$ is due to low-energy fission.

Another important difference between the two designs is the incorporation of the vanadium-titanium first wall. With the small-diameter proton beam, the original design was incapable of employing a first wall between the proton beam chamber and the liquid sodium target. With the spreading of the beam now possible, a first wall capable of withstanding the harsh radiation and thermal environment could be included; however, the first wall can function only as a window because the thickness required for it to serve as a structure component could not be adequately cooled. Also, it should be noted that the minimum first-wall hot-spot temperature of $875^{\circ} \mathrm{C}$ is still above recommended operating temperatures for steel. Finally, the first wall will have to be replaced every 90 FPD's to function within the DPA and gas production (hydrogen and helium) radiation-damage limits for steel. 
A few general conclusions can also be made in comparing the original and modified (semioptimized) target/blanket designs. First, the incorporation of the spread proton beam did not completely alleviate the problems associated with the original target/blanket design. Although the spread beam allowed a first wall to be introduced, the high power density at the center of the wall restricts its thickness; similarly, the peak power density in the target/blanket region restricts the fuel pebble size (to $0.5 \mathrm{~cm}$ ). However, the temperatures in both the wall and the fuel decrease rapidly with radius, as indicated in the power density profiles. Therefore, it is felt magnetic fields should be used to both spread and sweep the proton beam across the target/blanket region to lower the average beam density and, consequently, the peak power density. This would make the first-wall problems (i.e., damage, cooling, and structural capacity) and the target/blanket design problems (i.e., fuel pebble size, power densities, cycle length, etc.) appear more manageable.

A second general conclusion is evident from the negligible difference in the target/blanket performance for the two different reprocessing modes. The results for continuous on-line fuel reprocessing were only slightly worse than those for batch reprocessing: the ${ }^{233} \mathrm{U}$ production was somewhat lower, the ${ }^{228} \mathrm{Th}$ and ${ }^{232} \mathrm{U}$ concentrations were somewhat higher, and the thermal power was slightly higher. These results lead to the conclusion that the added cost and complexity of implementing continuous on-line fuel reprocessing are not worthwhile, and therefore the blanket should be operated in a batch reprocessing mode. It should be noted that the target/blanket does not contain a "packed" pebble bed, and therefore even burnup of the fuel should be attainable by redistribution of fuel pebbles due to coolant flow.

A final general conclusion is related to the dimensions of the ternary metal fuel region and its initial fuel requirements. As noted above, this region needs $15,100 \mathrm{~kg}$ of ${ }^{239} \mathrm{Pu}$ as initial fissile inventory, which is prohibitive. While the dimensions of this region and its fuel inventory were not investigated in the one-dimensional parameter optimization study, it is possible that the ternary metal fuel zone and possibly the thorium blanket zone were designed to extend too far in the axial direction. The axial power density profile in Fig. 14 shows a factor of 10 decrease in the fission power component within the first 80 to $90 \mathrm{~cm}$ of the ternary metal fuel zone, with the high-energy component contributing a negligible amount. Similarly, spatial maps of the total flux, ${ }^{239} \mathrm{Pu}(n, f)$ activity, ${ }^{238} \mathrm{U}(n, \gamma)$ activity, and ${ }^{232} \mathrm{Th}(n, \gamma)$ activity shown in Figs. 29-32, respectively, show sharp radial and axial falloffs, all of which indicate substantial over-design of the ternary metal zone. The final proof of over-design comes from the fact that the thorium blanket zone produces less than $20 \%$ of the total ${ }^{233} \mathrm{U}$, irregardless of cycle length or ${ }^{239} \mathrm{Pu}$ concentration. Therefore, the ternary metal zone probably could be decreased in volume by up to 50 to $60 \%$ without causing a substantial reduction in fissile fuel production. This would reduce the initial fissile inventory to approximately $7,000 \mathrm{~kg}$ of ${ }^{239} \mathrm{Pu}$, which appears more feasible.

In summary, the modified (semioptimized) TMF-ENFP target/blanket design exhibits more efficient utilization of the incident proton beam and yields a net fissile output that is a factor of 1.6 times greater than that of the original design. The major areas for concern mentioned above all have reasonable solutions which could be verified in future work. The ternary metal fuel has many advantages, including high spallation neutron production, good radiation-damage and heat-transfer characteristics, and relatively inexpensive reprocessing (pyrometallurgical). The liquid sodium coolant also gives moderately high spallation neutron production, has good heat-removal capability, and has reasonable pumping 


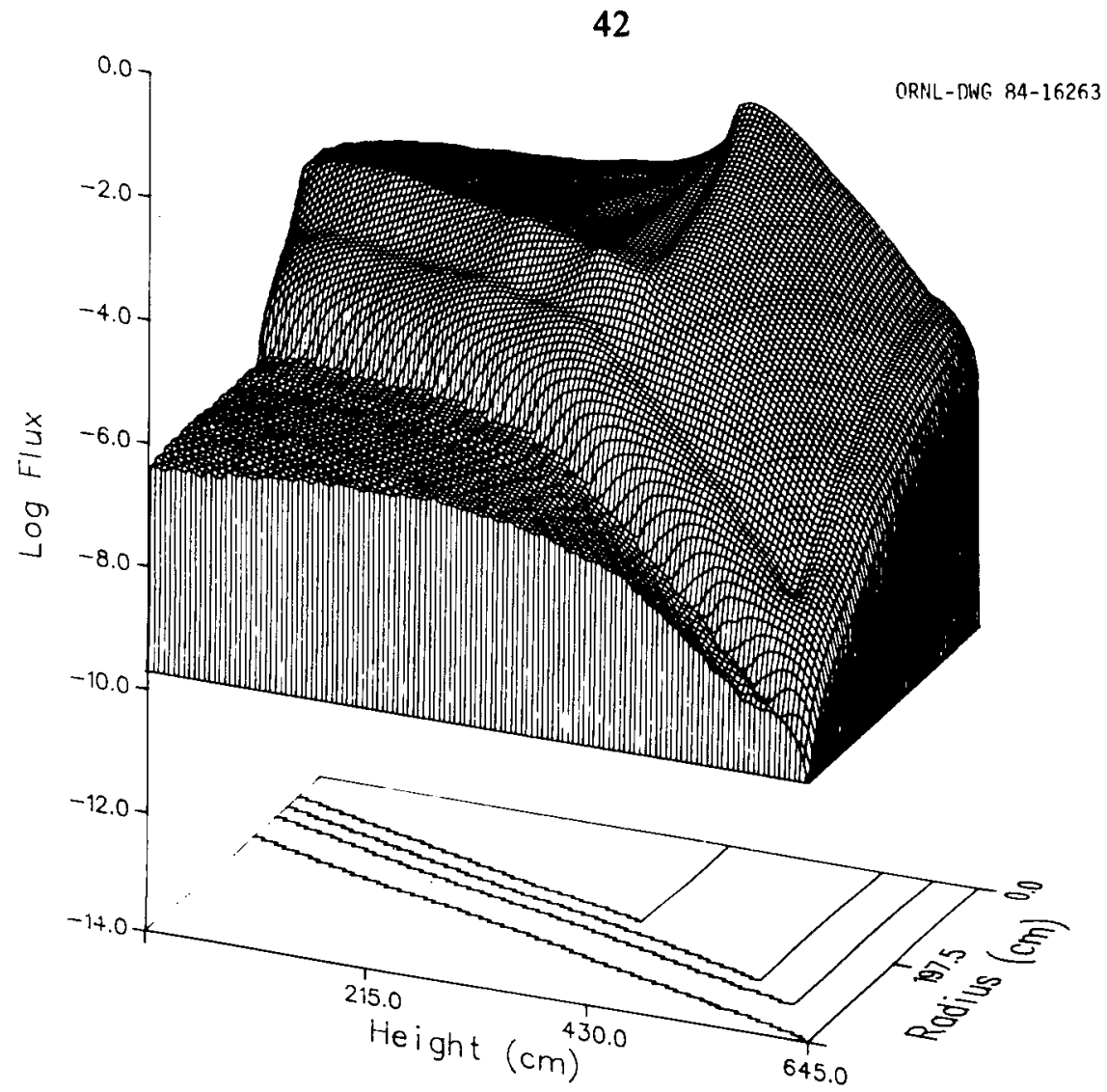

Fig. 29. Spatial map of the total flux from the modified TMF-ENFP target/blanket design.

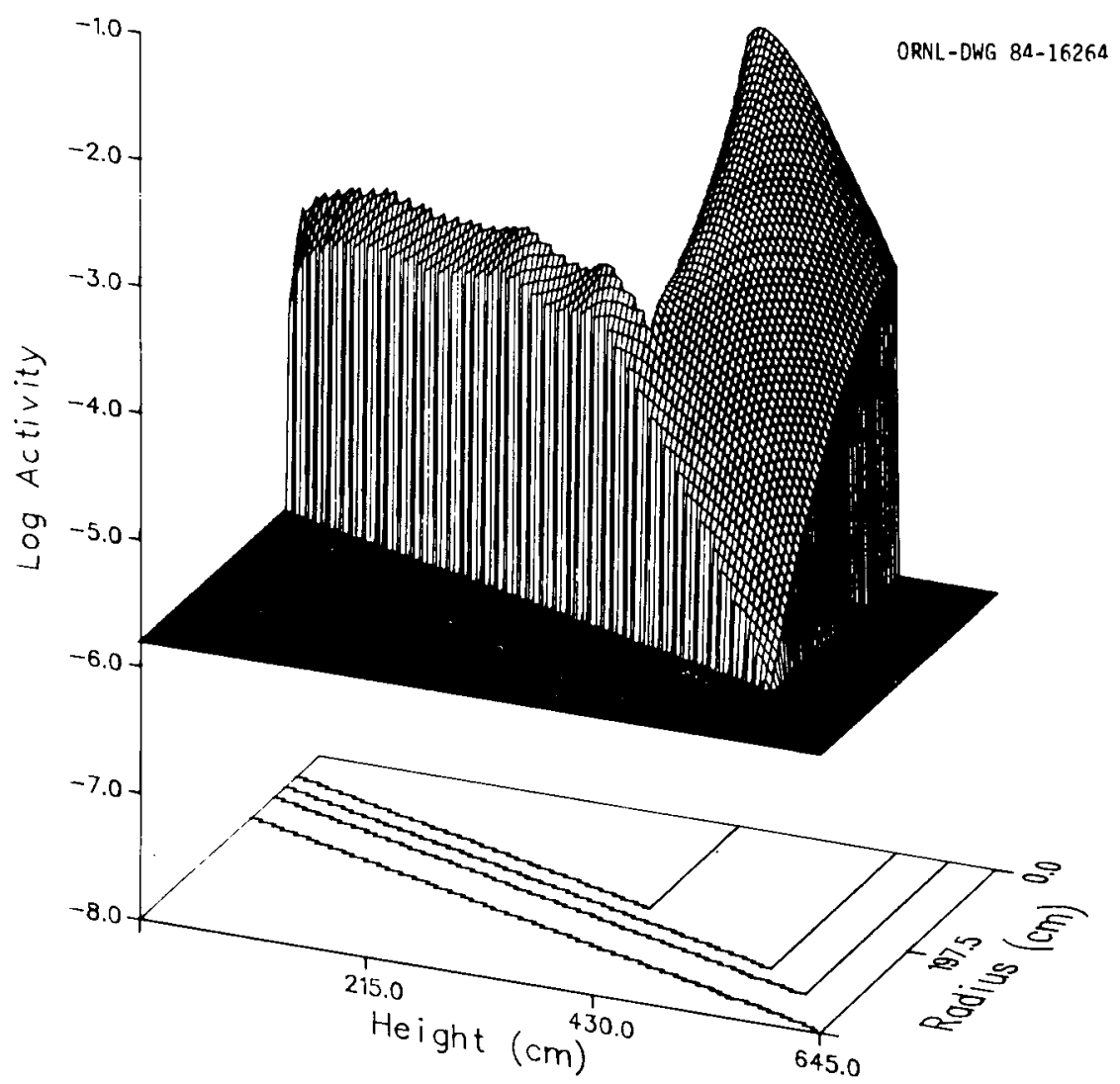

Fig. 30. Spatial map of the ${ }^{239} \mathrm{Pu}(n, f)$ activity for the modified TMF-ENFP target/blanket design. 


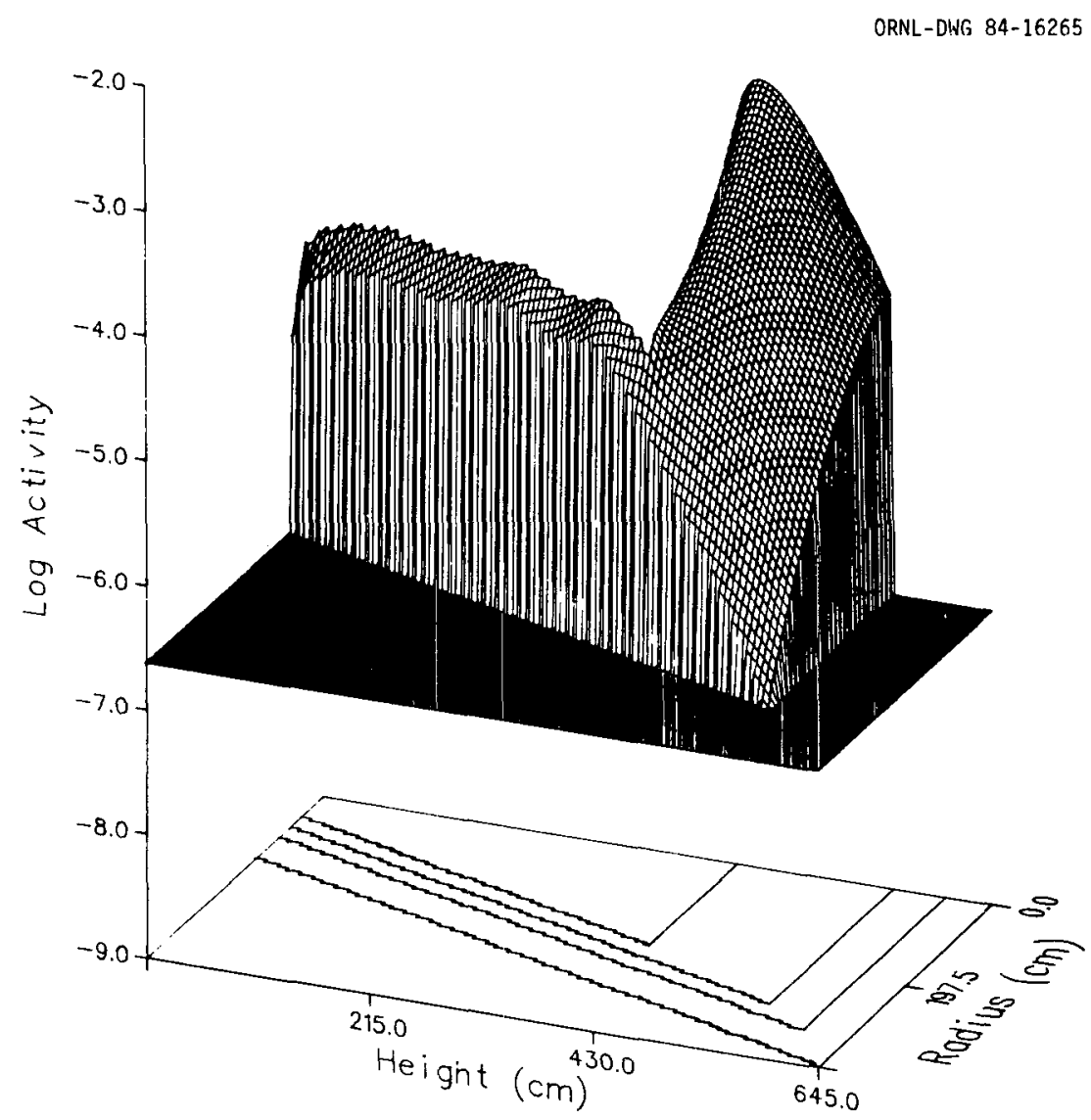

Fig. 31. Spatial map of the ${ }^{238} \mathrm{U}(n, \gamma)$ activity for the modified TMF-ENFP target/blanket design.

power requirements. Finally, the improved neutronic and thermal-hydraulic performance of the TMF-ENFP target/blanket indicates the technical feasibility for incorporation of a spread incident proton beam.

\subsection{RECOMMENDATIONS}

Some outstanding key design questions for both the accelerator and the target/blanket design need to be addressed (and overcome) before serious consideration can be given to the TMF-ENFP as an alternative fissile fuel producer or power source. Since this report is concerned only with the target/blanket design, the technological problem associated with the accelerator will not be discussed, and the interested reader should consult the references. Thus, the recommendations presented here all relate to the modified TMF-ENFP target/blanket design, which has both material and technological design problems that must be solved. The most outstanding problems are associated with (1) the initial proton beam density and distribution, (2) the first-wall design improvements, (3) strong temperature/power density gradients in radial and axial directions, and (4) initial fissile inventory. 


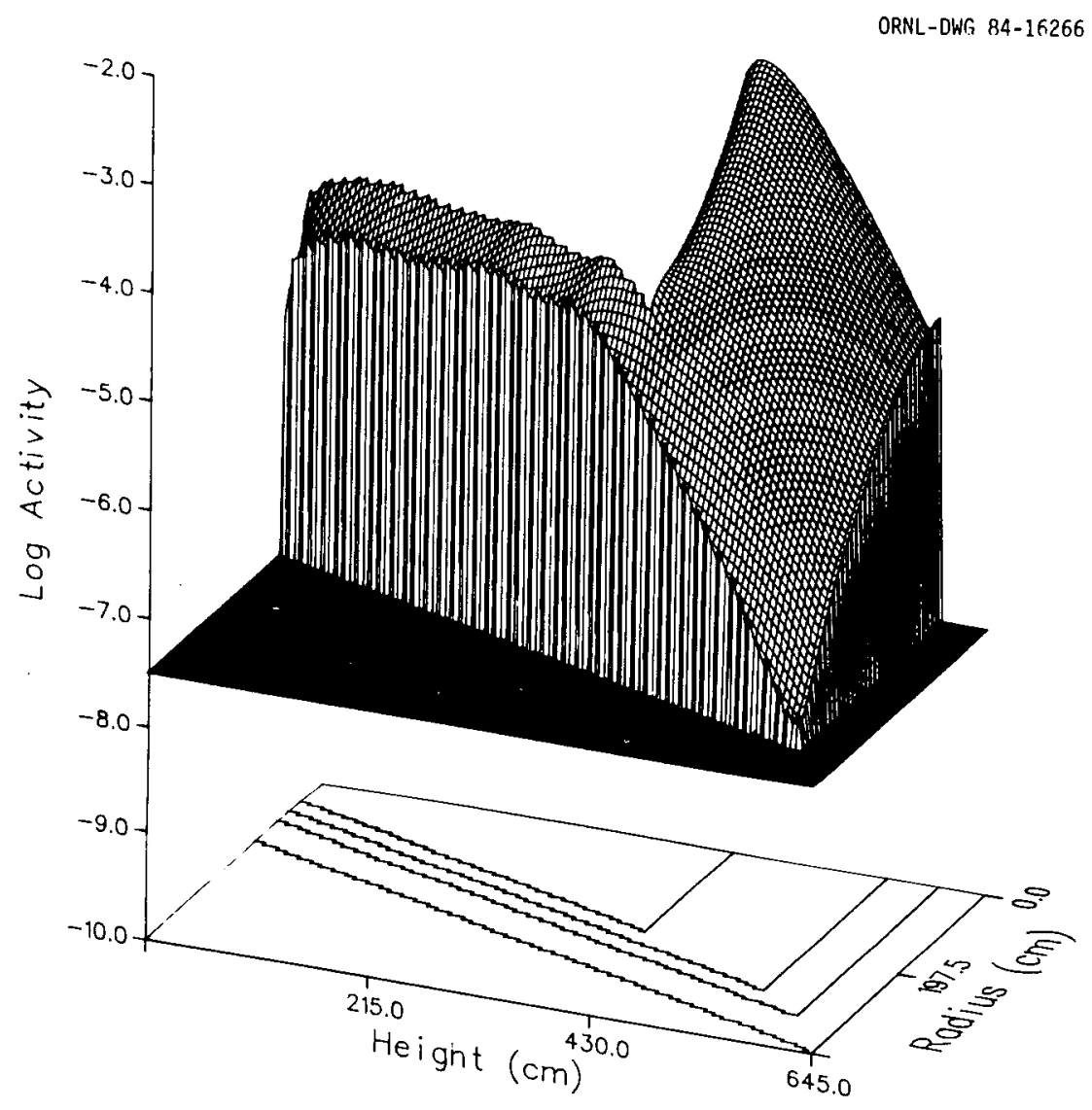

Fig. 32. Spatial map of the ${ }^{232} \mathrm{Th}(n, \gamma)$ activity for the modified TMF-ENFP target/blanket design.

Investigations to optimize the initial proton beam profile would help alleviate most of the problems mentioned above. While the dispersed beam proved to be advantageous, a flatter beam distribution would help solve both the first-wall problems and those produced by the severe temperature/power density gradients.

Improvements in the first-wall design also will require data on high-energy proton DPA and gas production damage, as well as industry standards for $\mathrm{V}-20 \% \mathrm{Ti}$ steel with respect to safe radiation damage limits and operating temperatures. In addition, the preferred functional capacity of the first wall should be structural, and efforts should be directed towards obtaining this goal via reduced damage from radiation and reduced centerline temperature through innovative heat-transfer design.

Finally, the target/blanket design should be optimized with respect to zone dimensions in order to reduce the initial fissile inventory requirements.

Any detailed future work on the TMF-ENFP should also investigate a few issues not addressed in this report. The follow-on study (after optimization of neutronic and thermal-hydraulic performance) should include a detailed economic analysis of the concept 
as an alternate fissile fuel and power producer. Presently, it is felt the method could become economically feasible if fissile fuel and power costs become sufficiently high. Incorporated into this study should be an investment risk analysis to determine system reliability and survivability under accident conditions.

Also, a study should be undertaken to investigate the TMF-ENFP in an alternative mode of operation. In particular, the target/blanket should be reanalyzed with respect to operation in a fission-suppressed mode, i.e., using beryllium as the multiplier. Should current social and political opposition to the use of ${ }^{239} \mathrm{Pu}$ continue, or should the inventory of ${ }^{239} \mathrm{Pu}$ be insufficient, an alternative mode of operation would be desirable. Another option worth investigating is utilizing the TMF-ENFP to also function as a fusile fuel (tritium) producer as well as a fissile fuel producer. This can be accomplished by employing a lithium-lead eutectic as the coolant. Should fusion power attain commercial operation, and this mode of operation (fusile and fissile fuel producer) appear feasible, then the TMF-ENFP would be an attractive source of fuel for both nuclear industries.

While the above discussion is clearly not all-inclusive, investigations into these areas would yield a fairly concise design from which potential production design studies could begin. In general, it is felt that the technology problems for the accelerator breeder reactor presented in this report are not extraordinary and, therefore, may well be alleviated before the economic conditions required to make fissile fuel production exist. 


\section{REFERENCES}

1. National Uranium Resource Evaluation Program, Preliminary Report, Energy Research and Development Administration, GJO-111 (1976).

2. W. I. Finch, Uranium and Thorium Resource Assessment and Exploration Research Program, U.S. Geological Survey Report 75-575 (1976).

3. Uranium: Resource, Production and Demand, Committee on Mineral Resources and the Environment (COMRATE), National Academy of Sciences - National Research Council (1976).

4. Problems of U.S. Uranium Resources and Supply to the Year 2010, Committee on Nuclear and Alternative Energy Systems (CONAES), National Academy of Science - National Research Council (1978).

5. R. E. Bell and H. M. Skarsgard, "Cross Sections of $(p, x n)$ Reactions in Isotopes of Lead and Bismuth," Canadian Journal of Physics 34, 745 (1956).

6. Livermore Research Laboratory, Status of the MTA Process, Livermore Research Laboratory, LRL-102 (1954).

7. E. E. Gross, The Absolute Neutron Spectrum from 190-MeV Proton Bombardment of Uranium, University of California, UCRL-3337 (1956).

8. W. A. Gibson et al., Low-Energy Neutron Production by High Energy Proton Bombardment of Thick Targets, Electronuclear Division Annual Progress Report for Period Ending December 31, 1965, Oak Ridge National Laboratory, ORNL-3940 (1966).

9. G. A. Bartholomew and P. R. Tunnicliffe, eds., The AECL Study for an Intense Neutron Generator, Atomic Energy of Canada Limited, AECL-2600 (1966).

10. J. S. Fraser, R. E. Green, J. W. Hilborn, and J. C. D. Milton (AECL); W. A. Gibson, E. E. Gross, and A. Zucker (ORNL), "Neutron Production in Thick Targets Bombarded by High Energy Protons," Physics in Canada 21(2), 17 (1965).

11. W. A. Coleman and R. G. Alsmiller, Jr., "Thermal Neutron Flux Generation by High Energy Protons," Nuclear Science and Engineering 34, 104 (1968).

12. V. G. Vasilkov et al., "Mean Number of Secondary Neutrons Evaporated from Nuclei Bombarded by High Energy Protons," Soviet Journal of Nuclear Physics 7, 68 (1968).

13. C. M. Van Atta, J. D. Lee, and W. Heckrotte, The Electronuclear Conversion of Fertile to Fissile Material, Lawrence Livermore Laboratory, University of California Radiation Laboratory, UCRL-52144, (1976).

14. G. A. Bartholomew et al., Accelerator Breeder Concept, Atomic Energy of Canada, LTD., AECL-6363 (1978).

15. R. A. Lewis et al., A Preliminary Study of the Accelerator Breeder Concept, Argonne National Laboratory, RSS-TM-8 (1977). 
16. F. R. Mynatt et al., Preliminary Report on the Promise of Accelerator Breeding and Converter Reactor Symbiosis (ABACS) as an Alternative Energy System, Oak Ridge National Laboratory, ORNL/TM-5750 (1977).

17. Proceedings of an Information Meeting on Accelerator Breeding, Brookhaven National Laboratory, NTIS CONF-770107 (1977).

18. T. J. Burns, D. E. Bartine, and J. P. Renier, Concept Evaluation of a Nuclear Design for Electro-nuclear Fuel Production: Evaluation of ORNL's Proposed TMF-ENFP, Oak Ridge National Laboratory, ORNL/TM-6828 (1979).

19. J. S. Frasier et al., A Review of Prospects for an Accelerator Breeder, Atomic Energy of Canada Limited, AECL-7260 (1981).

20. J. A. Horak, Materials Technology for Accelerator Production of Fissile Isotopes, Information Meeting on Accelerator Breeding, Brookhaven National Laboratory, CONF-770107 (1977).

21. B. Blumenthol, J. E. Sanecki, D. E. Busch, and D. R. O'Boyle, Thorium-Uranium-Plutonium Alloys as Potential Fast Power-Reactor Fuels, Argonne National Laboratory, ANL-7259 (1969).

22. Carroll F. Powell, Joseph H. Oxley, and John M. Blocker, Jr., Vapor Deposition, John Wiley and Sons, Inc., New York (1966).

23. C. R. Weisbin, R. W. Roussin et al., VITAMIN-E: An ENDF/B-V Multigroup Cross-Section Library for LMFBR Core and Shield, LWR Shield, Dosimetry, and Fusion Blanket Technology, Oak Ridge National Laboratory, ORNL5505/ENDF-274 (1979).

24. N. M. Greene, W. E. Ford, III et al., AMPX-II: A Modular Code System for Generating Coupled Multigroup Neutron/Gamma-Ray Cross-Section Libraries from Data in ENDF Format, Oak Ridge National Laboratory, ORNL/TM-3706 (1978).

25. G. C. Haynes, The AXMIX Program for Cross Section Mixing and Library Arrangement, Oak Ridge National Laboratory, ORNL/TM-5295 (1974).

26. O. W. Herman, COUPLE: A Scale System Module to Process Problem-Dependent Cross Sections and Neutron Spectral Data for ORIGEN-S Analysis, Oak Ridge National Laboratory, NUREG/CR-0200, ORNL/NUREG/CSD-2/V2/R1 (1981).

27. W. A. Rhoades and R. L. Childs, An Updated Version of the DOT 4 One- and TwoDimensional Neutron/Photon Transport Code, Oak Ridge National Laboratory, ORNL-5851 (1982).

28. T. W. Armstrong and K. C. Chandler, Operating Instructions for the High-Energy Nucleon-Meson Transport Code HETC, Oak Ridge National Laboratory, ORNL4744 (1972).

29. D. T. Ingersoll and C. O. Slater, DOGS - A Collection of Graphics for Support of Discrete Ordinates Codes, Oak Ridge National Laboratory, ORNL-TM-7188 (1980). 
30. D. C. Elrod, G. E. Giles, and W. D. Turner, HEATING6: A Multidimensional Heat Conduction Analysis with the Finite-Difference Formulation, Oak Ridge National Laboratory, NUREG/CR-0200, ORNL/NUREG/CSD-2/V2 (1981).

31. O. W. Herman and R. W. Westfall, ORIGEN-S: Scale System Module to Calculate Fuel Depletion, Actinide Transmutation, Fission Product Buildup and Decay, and Associated Radiation Source Terms, Oak Ridge National Laboratory, NUREG/CR-0200, ORNL/NUREG/CSD-2/V2/R1 (1981). 
ORNL/TM-8999

\section{INTERNAL DISTRIBUTION}

1. L. S. Abbott

2. R. G. Alsmiller, Jr.

3. J. B. Ball

4-8. D. E. Bartine

9. L. A. Berry

10. T. J. Burns

11. D. G. Cacuci

12. W. G. Craddick

13. H. L. Dodds

14-18. T. A. Gabriel

19. H. Hazelton

20. D. T. Ingersoll

21-25. J. O. Johnson

26. F. C. Maienschein

27. J. A. Martin

28. O. B. Morgan
29. J. P. Nichols

30. D. K. Olsen

31. M. J. Saltmarsh

32. H. E. Trammell

33. A. Zucker

34. P. W. Dickson, Jr. (Consultant)

35. G. H. Golub (Consultant)

36. R. M. Haralick (Consultant)

37. D. Steiner (Consultant)

38-39. Central Research Library

40. Y-12 Document Ref. Section

41-42. Laboratory Records Department

43. Laboratory Records ORNL, RC

44. ORNL Patent Office

45-49. EPMD Reports Office

\section{EXTERNAL DISTRIBUTION}

50. Office of the Assistant Manager for Energy Research and Development, Oak Ridge Operations Office, DOE, P.O. Box E, Oak Ridge, TN 37831 Attention: S. W. Ahrends/M. J. Rohr

51. T. W. Armstrong, SAI, P.O. Box 2807, LaJolla, CA 92038

52. Dr. Winfried Schmidt, Karlsruhe Nuclear Research Center, One Farragut Square South, Washington, DC 20006

53. Dr. P. F. Pasqua, Nuclear Engineering Bldg., University of Tennessee, Knoxville, TN

54. Dr. G. S. Bartholomew, Atomic Energy of Canada Limited, Chalk River, Canada

55. Dr. P. M. Garvey, Atomic Energy of Canada Limited, Chalk River, Canada

56. Dr. Jerry McMichaels, Atomic Energy of Canada Limited, Chalk River, Canada

57. Dr. B. M. Townes, Atomic Energy of Canada Limited, Chalk River, Canada

58. Dr. G. Bauer, Kernforschungsanlage, Jülich GmbH, Postfach 1913, D-5170, Jülich, West Germany

59. Dr. H. Brockmann, Kernforschungsanlage, Juilich GmbH, Postfach 1913, D-5170, Jülich, West Germany

60. Dr. J. Schelten, Kernforschungsanlage, Jülich GmbH, Postfach 1913, D-5170, Jülich, West Germany

61. Dr. Les Burris, Argonne National Laboratory, 9200 S. Cass Ave., Argonne, IL 60439

62. Dr. Caffrey, National Engineering Laboratory, P.O. Box 1625, Idaho Falls, ID 83415

63. Prof. R. Chiba, Department of Physics, Tokyo Institute of Technology, Ookayama, Meguro-ku, Tokyo, Japan 
64. Dr. Floyd Culler, Electric Power Research Institute, P.O. Box 10411, Palo Alto, CA 94304

65. Prof. Kazuo Furukawa, Institute of Research/Development, Hiratsuka, Kanagawa, 259-12, Japan

66. Dr. J. S. Gilmore, Los Alamos National Laboratory, Los Alamos, NM 87454

67. Dr. R. A. Jameson, Los Alamos National Laboratory, Los Alamos, NM 87454

68. Dr. G. J. Russel, Los Alamos National Laboratory, Los Alamos, NM 87454

69. Dr. S. O. Schriber, Los Alamos National Laboratory, Los Alamos, NM 87454

70. Prof. Motoharu Kimura, The Laboratory of Nuclear Science, Tohoku University, Sendai, Japan

71. Dr. J. R. Powell, Department of Nuclear Energy, Bldg. 701, Brookhaven National Laboratory, Upton, NY 11973

72. Dr. M. Steinberg, Department of Applied Science, Bldg. 526, Brookhaven National Laboratory, Upton, NY 11973

73. Dr. H. Takahashi, Department of Nuclear Energy, Bldg. 130, Brookhaven National Laboratory, Upton, NY 11973

74-100. Technical Information Center, U.S. DOE, Oak Ridge, TN 37830 